Prepared under the auspices of the U.S. Department of State

\title{
A Methodological Toolkit for Field Assessments of Artisanally Mined Alluvial Diamond Deposits
}

Techiniques and Methods $11<02$ 
Cover. View from the Tambaoura Escarpment, southwestern Mali, March 2007. Photography by Peter Chirico, U.S. Geological Survey. 


\section{A Methodological Toolkit for Field Assessments of Artisanally Mined Alluvial Diamond Deposits}

By Peter G. Chirico and Katherine C. Malpeli

Techniques and Methods 11-D2

Chapter 2 of

Section D, Field Survey Methods

Book 11, Collection and Delineation of Spatial Data 


\title{
U.S. Department of the Interior SALLY JEWELL, Secretary
}

\section{U.S. Geological Survey Suzette M. Kimball, Acting Director}

\author{
U.S. Geological Survey, Reston, Virginia: 2014
}

For more information on the USGS - the Federal source for science about the Earth, its natural and living resources, natural hazards, and the environment, visit http://www.usgs.gov or call 1-888-ASK-USGS.

For an overview of USGS information products, including maps, imagery, and publications, visit http://www.usgs.gov/pubprod

To order this and other USGS information products, visit http://store.usgs.gov

Any use of trade, firm, or product names is for descriptive purposes only and does not imply endorsement by the U.S. Government.

Although this information product, for the most part, is in the public domain, it also may contain copyrighted materials as noted in the text. Permission to reproduce copyrighted items must be secured from the copyright owner.

Suggested citation:

Chirico, P.G., and Malpeli, K.C., 2014, A methodological toolkit for field assessments of artisanally mined alluvial diamond deposits: U.S. Geological Survey Techniques and Methods book 11, chap. D2, 28 p., http://dx.doi.org/10.3133/tm11D2. 


\section{Contents}

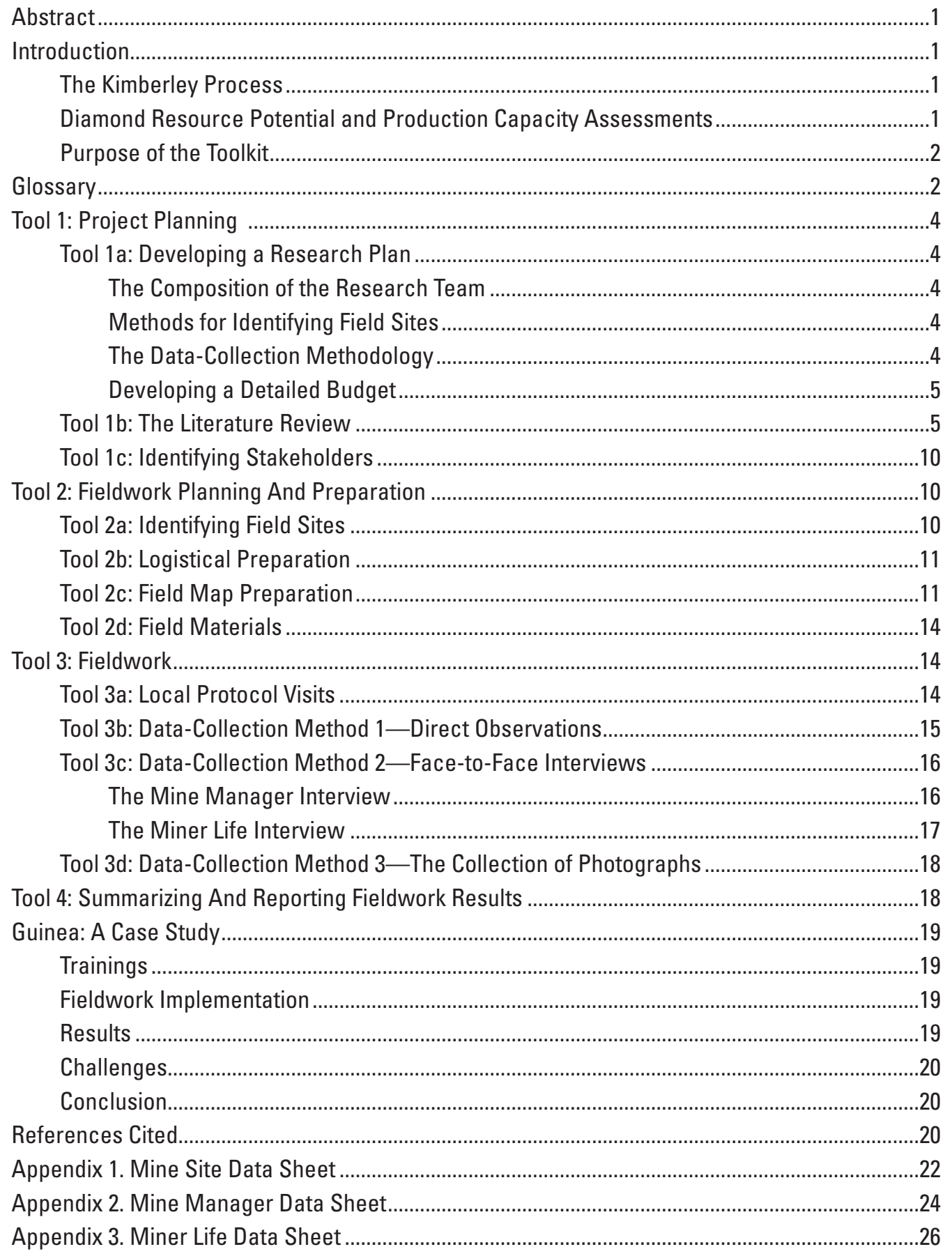




\section{Figures}

1. Example of a map showing the location of diamond occurrences in a country...............6

2. Diagram of a kimberlite pipe system and aerial photograph of an artisanally mined kimberlitic dike

3. Schematic profile of flood-plain geomorphology, showing alluvial flat and terrace deposits

4. A figure of common rough diamond shapes ..................................................................8

5. Sample profile of an artisanal mine site in Ghana illustrating the layering of gravels and overburden atop bedrock

6. Example of a concession location map with a corresponding table detailing grade

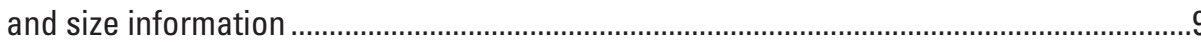

7. Example of an active artisanal diamond mining site, in the Coyah Prefecture of Guinea, identified via Google Earth

8. A comparison of oblique aerial photography and a Worldview-2 satellite image ..........12

9. Example of a typical field vehicle and lodging accomodations......................................13

10. Example of a base map with a satellite image background ..............................................13

11. Photos of a local prefecture visit: Elders at a mine site and a local mining

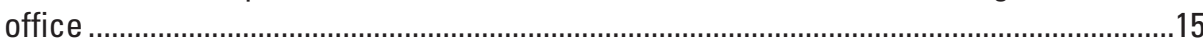

12. Example of a researcher collecting data in the field and a geomorphic profile.............16

13. Examples of typical photos taken while doing fieldwork at a mine site.............................18 


\title{
A Methodological Toolkit for Field Assessments of Artisanally Mined Alluvial Diamond Deposits
}

\author{
By Peter G. Chirico and Katherine C. Malpeli
}

\begin{abstract}
This toolkit provides a standardized checklist of critical issues relevant to artisanal mining-related field research. An integrated sociophysical geographic approach to collecting data at artisanal mine sites is outlined. The implementation and results of a multistakeholder approach to data collection, carried out in the assessment of Guinea's artisanally mined diamond deposits, also are summarized. This toolkit, based on recent and successful field campaigns in West Africa, has been developed as a reference document to assist other government agencies or organizations in collecting the data necessary for artisanal diamond mining or similar natural resource assessments.
\end{abstract}

\section{Introduction}

\section{The Kimberley Process}

The Kimberley Process (KP) is an international initiative whose goal is to prevent the trade of "conflict diamonds" while helping to protect legitimate trade through monitoring the production, exportation, and importation of rough diamonds throughout the world. Participating countries are required to (1) set up an internal system of controls and checks to prevent conflict diamonds from entering an imported or exported shipment of rough diamonds and (2) report the official amount of rough diamond production, imports, and exports each year to the KP. It is often difficult to obtain independent verification of the diamond-production statistics that are provided by countries, particularly those with an active artisanal mining sector. Some degree of independent verification, however, can be obtained through an understanding of a country's naturally occurring diamond resources and diamondproduction capacity. Studies that integrate these two components can produce a range of estimated values for a country's diamond production, which can then be compared with official production statistics provided to the KP.

\section{Diamond Resource Potential and Production Capacity Assessments}

To date, diamond resource potential and production capacity assessments have been completed in support of the KP for the following countries:

- The Republic of the Congo (Barthélémy and others, 2006)

- The Central African Republic (Chirico, Barthélémy, and Ngbokoto, 2010)

- Mali (Chirico, Barthélémy, and Koné, 2010)

- Ghana (Chirico, Malpeli, and others, 2010)

- Guinea (Chirico and others, 2012)

- Côte d'Ivoire (Chirico and Malpeli, 2013)

Each assessment is composed of multiple components and integrates various types of data. The assessment methodology can be divided into five phases:

- Phase 1: Literature review

- Phase 2: Remote sensing and Geographic Information Systems (GIS) data

- Phase 3: Field assessment

- Phase 4: Hydrologic and geomorphic modeling

- Phase 5: Data analysis

In phase 1, all available information related to the type, location, and characteristics of the diamond resources of the study country are gathered. Sources include scholarly articles, reports by private mining companies, international bodies, and institutions and nongovernmental organizations (NGOs), geologic maps, and geophysical studies. In phase 2, a GIS database of all known diamond occurrences is developed from the literature, and base-map data - such as rivers, roads, towns, and contours - are acquired or derived for the study area. Satellite imagery is acquired and analyzed to map the extent of all visible diamond mining areas and can further be used to track changes in mining activities over time. In 
phase 3, diamond mining sites within the study area are visited by a field team, and information on the terrain, geomorphology, geology, deposit characteristics, and the miners themselves are collected at each site. During phase 4, hydrologic and geomorphic analysis are performed to model the geomorphic modes of diamond occurrences as well as the deposits, streams, watersheds, and alluvial flat and terrace landforms of the sites. In phase 5, the data collected in the first four phases are analyzed to produce diamond resource and production capacity estimates for the country.

\section{Purpose of the Toolkit}

This toolkit focuses primarily on phase 3 of the methodology, the Field Assessment, and presents an approach which has proven successful for collecting the type of data required for implementing a diamond resource and production capacity assessment. The outlined tools provide a standardized checklist of critical issues relevant to artisanal mining-related field research. Previous toolkits geared towards researchers in the field of artisanal and small-scale mining (ASM) have covered topics such as gender dimensions of ASM and baseline assessments of ASM activities in protected areas (Eftimie and others, 2012; Hinton and Hollestelle, 2012; Noetstaller and others, 2004). There is also an ample body of peer-reviewed journal articles exploring the methodological challenges of baseline and survey work in the ASM environments that may serve as a resource for researchers.

The methodology outlined in this toolkit is an integrated sociophysical geographic approach to collecting data on artisanal mining. A diversity of data concerning variables such as the location and extent of mining activities, the number of active miners, and the geologic nature of the mined deposits is essential for evaluating and monitoring a country's diamond deposits and for ensuring that conflict diamonds do not enter the legitimate diamond trade.

The implementation of a multistakeholder approach for field data gathering is an important step towards ensuring that the physical- and social-science data necessary for the resource assessments are collected transparently and that the needs of all parties involved - international industry, national government, local communities, and civil societyare addressed. Many ASM studies have been conducted by individuals and organizations who have not used a multistakeholder approach. The competence of the researchers is the primary factor in the success of any field research, regardless of the number and type of stakeholders involved. However, a multistakeholder approach broadens the perspectives of the data-collection team and stimulates collaboration between often disparate groups, through the sharing of perspectives, skills, and capabilities; further, such an approach helps draw linkages between organizations and government agencies at the local, regional, and national levels. A model was developed in which members of the host-country's mining ministry and civil-society organizations collaborate in the collection of field data and receive international support from the KP. This model was implemented in the assessment of Guinea's artisanally mined diamond deposits; through that effort, the multistakeholder approach resulted in data collected by a tripartite team that could then be incorporated into a comprehensive assessment of Guinea's diamond deposits, which is the most up-todate and inclusive assessment of its kind, numbering 40 sites in all (Chirico and others, 2012). The successful Guinea model provides the primary reference point for this toolkit.

This toolkit has been developed as a reference document to assist other government agencies or organizations in collecting the data necessary for artisanal diamond mining or similar natural resource assessments. Every attempt has been made to include as much detail as is required for such an undertaking, but some details had to be omitted in order to create a succinct document. Therefore, this toolkit is not an exhaustive treatment of every situation one may encounter during fieldwork in remote and challenging terrain, nor is it an absolute reference for how ASM studies must be executed. This toolkit is intended instead to provide a detailed guideline for ASM field data gathering, based on our recent and successful field campaigns.

\section{Glossary}

Alluvial deposit (Alluvium) - A general term for clay, silt, sand, gravel, or similar unconsolidated detrital material deposited during relatively recent geologic time by a stream or other body of running water, as sorted or semisorted sediment in the bed of the stream or on its flood plain or delta (Neuendorf and others, 2005). Alluvial diamond deposits are typically comprised of overburden and gravel layers. There can be multiple gravel layers within one deposit, though they are not all diamondiferous. The richest gravel layer is typically found just above the bedrock. This is because during transport, the heaviest materials (such as diamonds) concentrate at the bedrock.

Alluvial flat-A small alluvial plain bordering a river and upon which sediments are deposited during periods of flood.

Alluvial plain - A level or gently sloping tract or slightly undulating land surface produced by extensive deposition of alluvium, usually adjacent to a river that periodically overflows its banks; it may be situated on a flood plain, a delta, or an alluvial fan (Neuendorf and others, 2005).

Artisanal and Small-Scale Mining (ASM) - Although there is no single definition of ASM, several recurrent criteria are commonly incorporated into the multiple definitions which attempt to distinguish ASM from large-scale mining. These criteria include the physical size of the mine, the number of workers, the level of financial investment, the organizational structure of the mining activities, and the degree of mechanization. ASM involves the use of rudimentary tools 
and labor-intensive techniques for extracting and processing mineralized ore.

Base map-A map showing essential information about a study area, such as elevation and basic features (rivers, roads, towns).

Bedrock-A general term for the consolidated rock underlying superficial material.

Colluvial deposit (Colluvium) - A general term applied to any loose, heterogeneous, and incoherent mass of soil material and (or) rock fragments deposited by rainwash, sheetwash, or slow continuous downhill creep, usually collecting at the base of gentle slopes or hillsides (Neuendorf and others, 2005).

Eluvial deposit (Eluvium) - An accumulation of rock debris produced in situ from the weathering of the primary source rock.

Exploration-The act of searching for undiscovered mineral deposits, also known as prospecting. This can include geological reconnaissance, such as geophysical and geochemical methods, as well as surface and underground workings.

Extraction-The process of removing mineralized ore from the Earth and the process of separating the ore from the total material mined.

Geomorphology - The study of the classification, description, nature, origin, processes, and development of present landforms and their relationships to underlying structures, and of the history of geologic changes as recorded by these surface features (Neuendorf and others, 2005).

Gravel grade - The relative quantity or percentage of ore-mineral content within one cubic meter of gravel. For diamond deposits, it is expressed as carats of diamond per cubic meter $\left(\mathrm{kt} / \mathrm{m}^{3}\right)$.

High terrace (see Terrace)

Kimberlite - A primary source rock of diamonds. Kimberlites come in the form of pipes (diatremes), dikes, sills, and blows (small, lens-shaped dike enlargements in the root zone of diatremes). Kimberlites tend to occur in clusters of more than 1 to over 100. Mineralogically, kimberlite, which is a porphyritic volcanic rock, consists of olivine phenocrysts and olivine megacrysts, pyroxene, phlogopite, and perovskite. Kimberlites are divided into two types: Group I Kimberlites and Group II Kimberlites. The former are found all over the world and are derived from a relatively primitive mantle source, probably the asthenosphere, whereas the latter are known only in southern Africa and are thought to originate from metasomatically enriched parts of the lithosphere (Erlich and Hausel, 2002).

Lamproite - A primary source rock of diamond deposits. They are ultrapotassic mantle-derived volcanic and subvolcanic rocks, and form diatremes, dikes, sills, vents, flows, and scoria cones. Similar to kimberlites, lamproites tend to occur in clusters of more than 1 to over 100. Lamproites are found within ancient cratons, along cratonized boundaries within orogenic zones, and within deep-seated transform fault zones. Diamonds found in lamproites are generally smaller than those found in kimberlites, and large diamonds are uncommon (Erlich and Hausel, 2002).

Lithology - The description or physical character of a rock, such as its color, mineralogic composition, and grain size (Neuendorf and others, 2005).

Low terrace (see Terrace)

Ore grade - The relative quantity or percentage of oremineral content in an ore body (such as a kimberlite pipe), and is typically expressed as carats of diamond per hundred tons (cpht).

Outcrop-The part of a geologic formation that appears at the surface.

Overburden layer-The barren unconsolidated sediment layer that lies above the mineralized gravel layer and must be removed prior to mining. The thickness of the overburden layer varies from deposit to deposit. Within a particular river system, the alluvial flats contain thicker overburden layers than terraces. Overburden thickness generally decreases as terrace elevation increases.

Primary deposit - A mineral deposit that was formed at the same time as the rock enclosing it and has remained within the source rock. For example, diamonds mined directly from a kimberlitic dike would be considered primary deposits.

Production capacity - The current volume of diamonds (calculated as total number of carats) which can be produced utilizing current human and physical resources. It is a measure of the current state of the diamond mining sector based on data such as gravel grade, the number of active miners, and the number of days miners work per year.

Resource potential-The total diamond reserve estimated to be remaining in the study area.

Secondary deposit - Deposits which have been removed from their source rocks due to the processes of weathering and erosion. Secondary deposits are subdivided into eluvial, colluvial, and alluvial deposits.

Source (or host) rock-The rock from which fragments and other detached pieces have been removed to form a later rock. It is the geologic formation in which the minerals originate. Kimberlites and lamproites are two examples of diamond deposit source rocks. Cratonic environments, a part of the Earth's crust which has stabilized and has not been deformed for a long period of time, are favorable for the emplacement of diamondiferous host rocks (Erlich and Hausel, 2002).

Stratigraphy - The geologic study of the form, arrangement, geographic distribution, chronologic succession, classification, and correlation and mutual relationships of rock strata. It is the arrangement of strata, especially concerning the geographic location and chronologic order of sequence.

Terrace - A large bench or steplike ledge that breaks the continuity of a slope. A terrace commonly occurs along the margin and above the level of a body of water, marking a former water level (Neuendorf and others, 2005). Because terraces are landforms that were at one time the active channel of a river, they can be used to determine changes in base level, climate, or tectonic activity. Terrace deposits in general have lower and more irregular gravel grades, though they do have 
the potential to contain large diamond deposits and are often easier to exploit because they have thinner overburden layers. Terraces may be situated directly on the bedrock, or they may be stacked on top of each other, evidence of a complicated river history. Terraces exist at different elevations above base level, and can be termed "low terrace," "middle terrace," or "high terrace," on the basis of their respective relative elevations. Using this terminology, a "low terrace" refers to a terrace that is low in elevation (for example, 1-3 meters (m) above base level), whereas a "high terrace" refers to a terrace that is high in elevation (for example, $10 \mathrm{~m}$ above base level). The presence of different terrace levels is determined by the unique history and characteristics of each river system.

\section{Tool 1: Project Planning}

Prior to beginning fieldwork, several steps are necessary to ensure that the time spent in the field is as efficient and effective as possible. The following section outlines tools to assist the researcher with forming a research plan, selecting a research team, developing a comprehensive understanding of the deposits which will be assessed, locating appropriate field sites, identifying stakeholders, and logistical planning.

\section{Tool 1a: Developing a Research Plan}

A detailed research plan is devised before fieldwork begins. Although all foreseeable factors are initially addressed and outlined in the research plan, the plan will likely change somewhat as fieldwork preparations continue to progress; so, flexibility during this process is key.

A clearly stated research goal is a critical part of the research plan and essential for successful fieldwork. The goal helps to identify the important aspects of the field mission and establish the boundaries between what can be accomplished and what may be outside of the scope of the project. For example, establishing a goal to sample several ASM sites in a region of reported new mining activity is vastly different from the goal of a comprehensive countrywide survey of ASM sites. Each goal requires a different level of time and resource investment, and each will result in different output deliverables. Keep these questions in mind when establishing the research goal:

- What is the scale of the research (local, regional, or national)?

- What deliverables will be produced as a result, and with whom will these deliverables be shared (for example, local communities and miners, national government, the KP, NGOs)?

Answering such questions prior to data collection will help ensure that time in the field is spent effectively, by providing a clear vision of what type of data needs to be collected and how the data will be reported.

\section{The Composition of the Research Team}

- On the basis of the stated goals of the research, a suitable team can be recruited or selected to address the multiple skills required to collect the appropriate field data.

- A research team can include one or more members from the following groups:

- Geologic and other governmental experts

- Representatives from the mining ministry or delegated representatives

- Representatives with expertise in geology and mineral occurrences

- Mining engineers familiar with ASM mining activities and techniques

- Civil-society representatives

- Community representatives

- Industry representatives

- Ideally, at least one of the team members will be familiar with the local dialect and the official national language. If none of them are, a local translator can be hired as a team member.

\section{Methods for Identifying Field Sites}

- Identify which factors will be considered when determining the number and location of field sites.

- Where are the largest active mining sites located? How will they be identified?

- Literature review, satellite imagery, discussions with local representatives

- What is the condition of transportation infrastructure in and around the sites?

- Are the sites close to a town with lodging accommodations?

-What are the temporal, seasonal, and financial constraints?

\section{The Data-Collection Methodology}

- Identify the methods that will be used for data collection. The approach outlined in this toolkit consists of site observations in combination with face-toface interviews as a means for collecting data. 


\section{Developing a Detailed Budget}

- Develop a detailed budget as part of the research plan. The budget takes into account the amount of time available and (or) needed to do fieldwork, logistical issues such as travel and accommodation costs, per diem amounts for team members, and so forth.

\section{Tool 1b: The Literature Review}

The literature review step assists the researcher in developing a comprehensive understanding of the diamond deposits within the study country and the socioeconomic context within which ASM occurs so that informed decisions can be made on where to do fieldwork. Types of literature include but are not limited to peer-reviewed journal articles, geologic and geophysical maps, published and unpublished mining company reports, previous mineral assessments, and KP statistics.

Sources of literature include the libraries of the hostcountry's geologic and mineral agencies; host-country university libraries; the offices of NGOs and foreign assistance agencies, such as the World Bank and the U.S. Agency for International Development (USAID); the libraries of foreign country governments which have performed previous minerals and geologic research in the study area; and Internet resources.

Several published works in particular provide a good starting point from which to launch research on diamond deposits in Africa:

- Bardet, M.G., 1973, Géologie du diamant, généralités: Bureau de Recherches Géologiques et Minières Memoir, v. 1, no. 83, 235 p.

- A summary of the characteristics and depositional nature of primary and secondary diamond deposits.

- Bardet, M.G., 1974, Géologie du diamant, gisements de diamant d'Afrique: Bureau de Recherches Géologiques et Minières Memoir, v. 2, no. 83, 223 p.

- A summary of the location and characteristics of Africa's diamond deposits, by region and country.

- Janse, A.J.A., and Sheahan, P.A., 1995, Catalogue of world wide diamond and kimberlite occurrences-A selective and annotative approach: Journal of Geochemical Exploration, v. 53, p. 73-111.

- A summary of the location, formation, and prospecting of the world's major diamond deposits and kimberlites, by continent.

- Janse, A.J.A., 1995, A history of diamond sources in Africa-Part I: Gems and gemology, v. 31, no. 4, p. 228-255.
- A summary of the history of diamond discoveries and mining activities in southern and central Africa, from the 19th century to the present.

- Janse, A.J.A., 1996, A history of diamond sources in Africa-Part II: Gems and g emology, v. 32, no. 1, p. 2-30.

- A summary of the history of diamond discoveries in eastern and western Africa, plus the history of diamond prospecting, mining, and production activities across the continent.

- Janse, A.J.A., 2007, Global rough diamond production since 1870: Gems and gemology, v. 43, no. 2 , p. $98-119$.

- An analysis of global annual rough diamond production from 1870 to 2005 .

- Kimberley Process, 2004-2013, Kimberley Process Rough Diamond Statistics, available at $w w w$. kimberleyprocessstatistics.org.

- A compilation of statistical data of Kimberley Process participants for trade and production of rough diamonds, by value and volume.

- U.S. Geological Survey (USGS), International Minerals Statistics and Information, available at minerals.usgs.gov/minerals/pubs/country/index. html\#pubs.

- A compilation of all annually produced, nationalscale international minerals reports published by the USGS.

Certain data about the deposits can be particularly useful during the analysis phase of the assessment and are specifically searched for during the literature review process:

- Information on the geographic location of all diamond occurrences and deposits (both active and inactive):

- The most specific geographic information that can be obtained is the precise geographic coordinates of the deposit or occurrence. These coordinates may be written in degrees, minutes, seconds (for example, lat $10^{\circ} 45^{\prime} 15^{\prime \prime} \mathrm{N}$., long $13^{\circ} 20^{\prime} 10^{\prime \prime} \mathrm{W}$.); decimal degrees (for example, lat 10.33, long-13.34); or Universal Transverse Mercator (UTM) easting and northing (for example, 715356, 1058813). The coordinates corresponding to occurrences may be written out in text documents, or they can be extracted from maps showing the location of the occurrence (for example, fig. 1). If possible, such maps should be scanned and geographically referenced using a GIS to identify the exact coordinates of occurrences. 


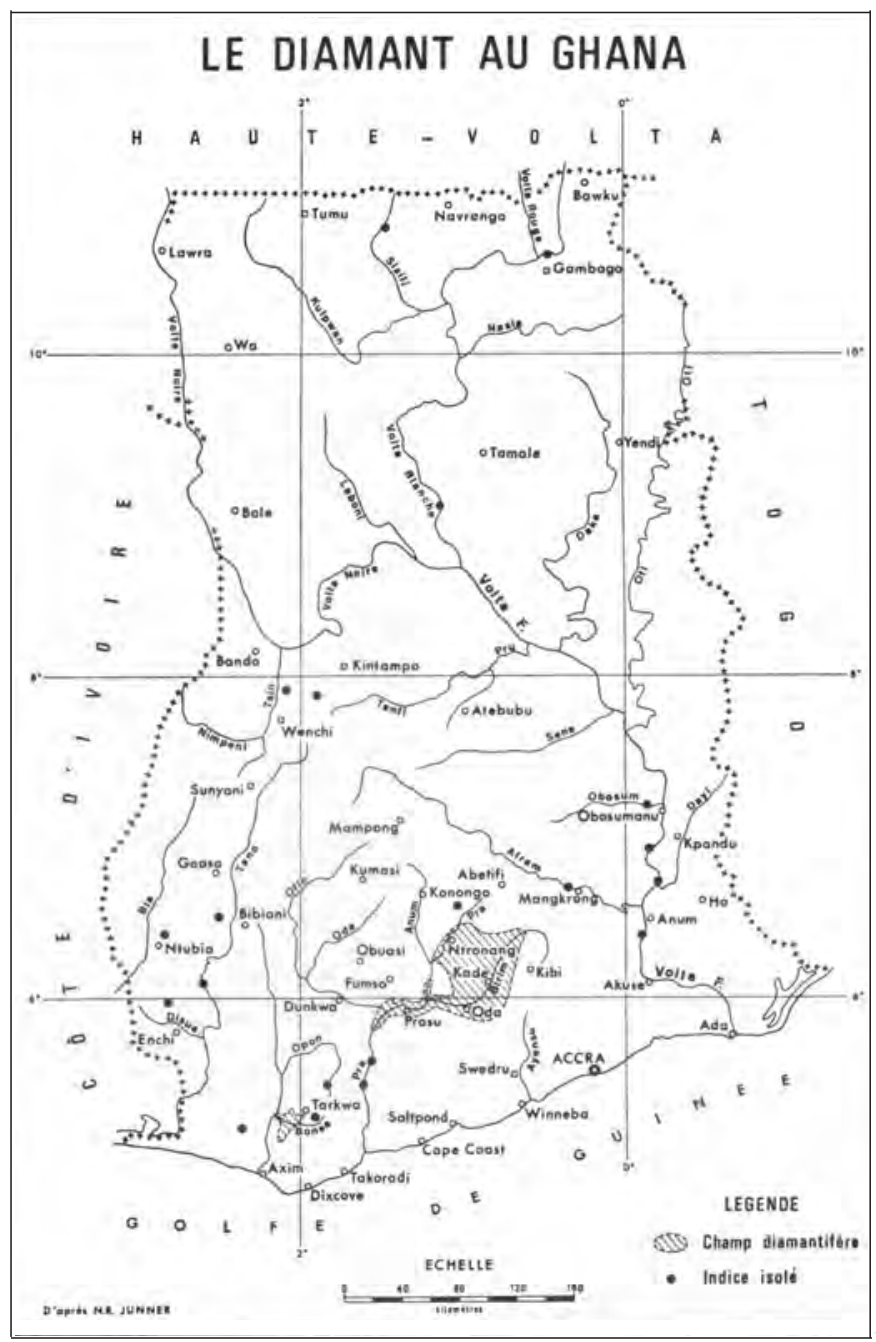

Figure 1. Example of a map showing the location of diamond occurrences in a country. Diamond occurrences are characterized as black dots on the map. By using the geographic coordinates, this map could be geographically referenced in a geographic information system (GIS) (from Bardet, 1974).

- Oftentimes, such precise coordinates are not available. In such cases, other information such as the name of a nearby river, town or village, or prefecture can be used to more generally locate the occurrence.

- Local knowledge is a very important aspect of identifying the locations of mining zones. Interviews and discussions with local authorities, tribal elders, diamond buyers, and miners often reveal information about the location, history, and productivity of deposits.

- The location of all known primary diamond deposits, such as kimberlitic pipes and dikes:

\section{- Note on primary versus secondary diamond deposits:}

- Primary diamond deposits are those which have remained within the original source rock. Source rocks include kimberlitic pipes (diatremes), dikes, sills, blows, and lamproites (fig. 2).

- In contrast, secondary deposits are those which have been transported from their source rocks via the processes of weathering and erosion; they are subdivided into eluvial, colluvial, and alluvial deposits.

- Eluvial deposits are developed in situ from the weathering of the primary source rock.

- Colluvial deposits consist of weathered rock which has been transported downslope by gravity, typically found at the foot of slopes.

- Alluvial deposits have been transported downstream from their source rock by river systems and are eventually deposited over potentially vast areas within a river's channel bed, alluvial flat, or terraces (fig. 3).

- Channel deposits are those which are found in bedrock potholes of the active channel's riverbed, whereas alluvial flat deposits are those located in the current flood plain. Terraces are formed by either a decrease in stream base level, which results from sea-level or climate changes, or as a result of the tectonic uplift of the landscape. In either case, downward erosion occurs and terraces develop in what was once the former flood plain, above the newly formed flood plain and channel.

- The geologic conditions (lithology, stratigraphy, and structural controls) that are known to host diamond deposits in the study country:

- Acquiring information on the age and type of the bedrock formations in the region that are known to contain diamond deposits helps in understanding the geologic history and formation of the deposits, as well as the potential location of other deposits which may not have been previously mapped. For example, it is known that diverse lithologies - particularly those which have been metamorphosed, folded, sheared, and faulted - are ideal for alluvial diamond concentration. Furthermore, dense and erosion-resistant bedrock helps concentrate minerals, whereas soft bedrock tends to dilute mineral concentration (Marshall and Baxter-Brown, 1995).

- Stratigraphy.-Stratigraphy is the interpretation of rocks in terms of their mode of origin and geologic history. 

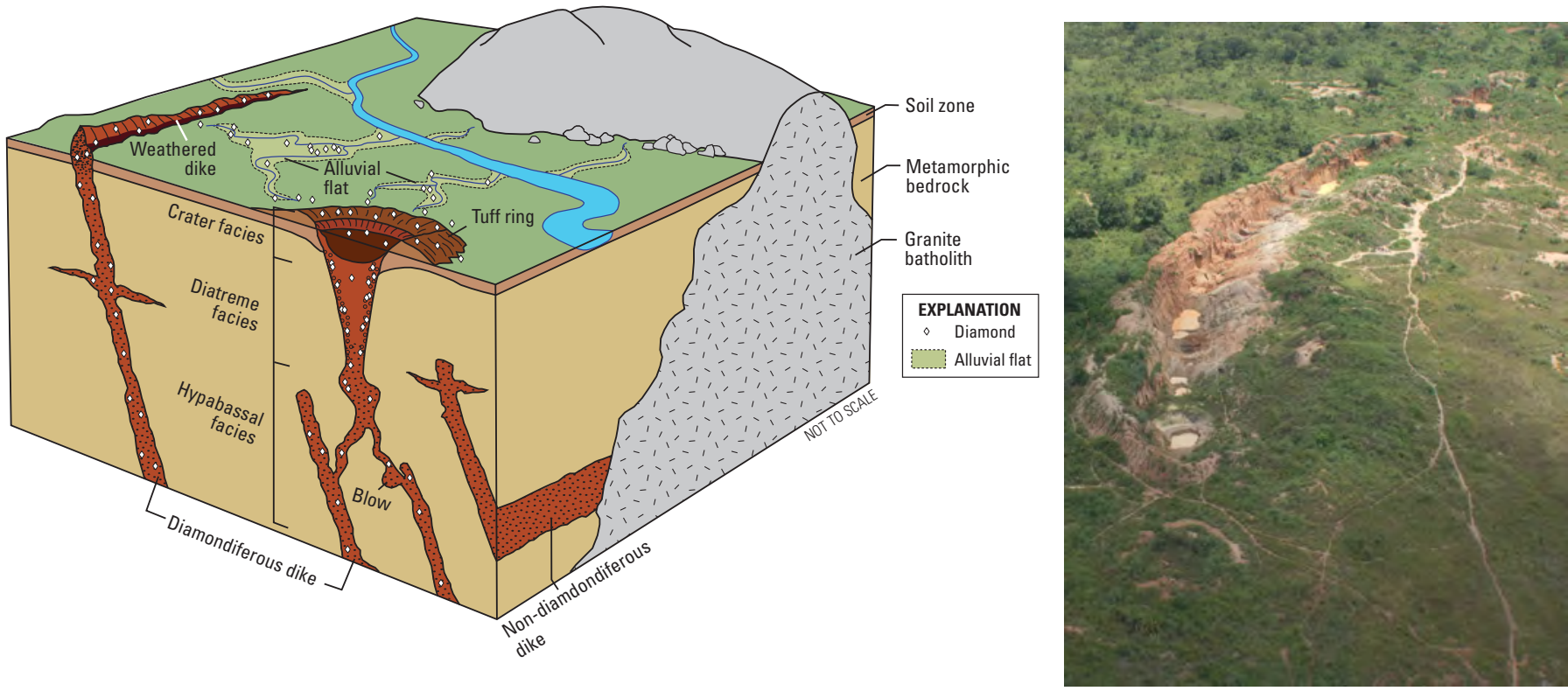

Figure 2. Diagram of a kimberlite pipe system (from Chirico and Malpeli, 2013) and aerial photograph of an artisanally mined kimberlitic dike.

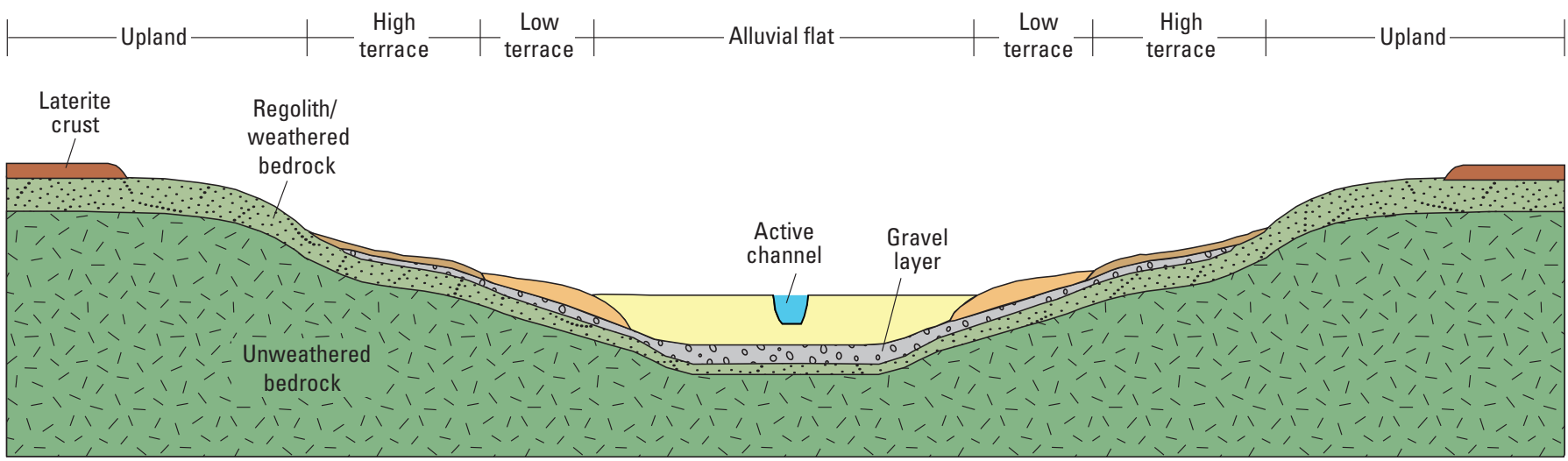

Figure 3. Schematic profile of flood-plain geomorphology, showing alluvial flat and terrace deposits (from Chirico, Malpeli, and others, 2010).

- Lithology.-The lithology of a rock refers to its physical characteristics, such as its color, mineralogic composition, and grain size.

- Data on the grade of known deposits:

- Grade provides a measure of the quality of a particular deposit. Two types of grade measurements typically are used in exploration or geologic reports: ore grade, which refers to the grade of primary deposits; and gravel grade, which refers to the grade of alluvial deposits.
- Ore grade is the relative quantity or percentage of ore-mineral content in an ore body (such as a kimberlite pipe) and is typically expressed as carats of diamond per hundred tons (cpht).

- Gravel grade is the relative quantity or percentage of ore-mineral content within 1 cubic meter of gravel, expressed as carats of diamond per cubic meter $\left(\mathrm{ct} / \mathrm{m}^{3}\right.$ or $\left.\mathrm{kt} / \mathrm{m}^{3}\right)$. Gravel grade varies by geomorphic expression, owing to the differing erosional histories and clustered nature of alluvial diamond deposits. Several studies have found that lower average grades are found in terrace deposits as compared to alluvial flat deposits and 
that mineral retention appears to decrease as slope increases (Hall and others, 1985). The confluences of major tributaries are also zones with potentially high diamond concentration. Gravel grade is typically estimated by shallow drilling and pit excavation, in which the number of diamonds per sample is counted to calculate the grade. Such activities are typically part of the exploratory phase of bulk sampling performed by industrial mining companies and are used to determine the economic viability of a deposit.

- Characteristics of the diamonds themselves, including size, weight, shape, color, and types of inclusions:

- Typically referred to as the "4 C's," carat weight, color, clarity, and shape (once a rough stone is polished, this is referred to as "cut"), these characteristics are used to determine the economic value of a particular diamond (fig. 4). Although each individual diamond is unique, diamonds found within the same deposit often share similar characteristics, allowing generalizations about the economic viability of a deposit to be made.

- Diamond size (measured in millimeters or carats) is another important characteristic to research. Diamond size typically decreases as distance from the source rock increases because smaller diamonds are more easily transported downstream (Erlich and Hausel, 2002). Therefore, the size of diamonds within a particular deposit can be used to estimate, if unknown, the distance of the deposit from the source rock.

- Information on the thickness of the diamondiferous gravel layer and the overburden material lying above the gravel (fig. 5):

- Alluvial diamond deposits are typically stratified into layers of overburden followed by layers of gravel, either sterile or mineralized. It is within the gravel layer overlying the bedrock that diamonds concentrate. Overburden, the unconsolidated sediment layer that lies above the gravel layer, is an important characteristic which greatly influences the accessibility of a deposit; the thinner the overburden layer, the more easily exploitable the deposit. Primary and eluvial deposits generally have minimal overburden. Secondary alluvial deposits have varying overburden thicknesses although, in general, high terraces have the thinnest overburden layers, followed by low terraces and alluvial flats. Overburden thickness in West and Central Africa can range from several centimeters to more than $30 \mathrm{~m}$.

- The results of any previous diamond resource assessments that have been performed:

- Oftentimes, an industrial mining company will produce a resource assessment for its mining concession. Although such assessments are typically completed at a relatively small scale, researchers should
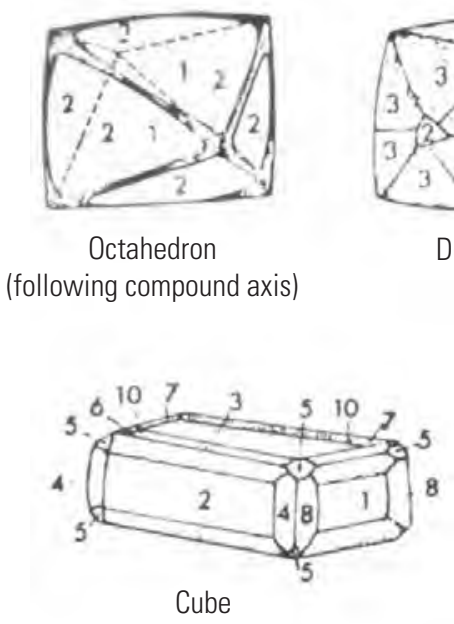

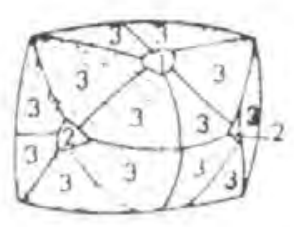

Dodecahedron

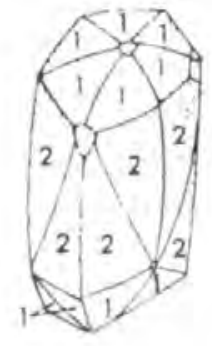

Dodecahedron (following compound axis)

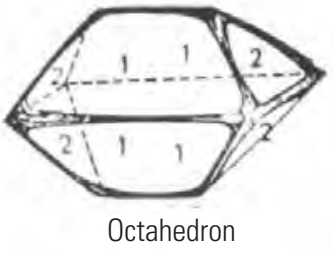

(following binary axis)

Figure 4. A figure of common rough diamond shapes (modified from Bardet, 1974).
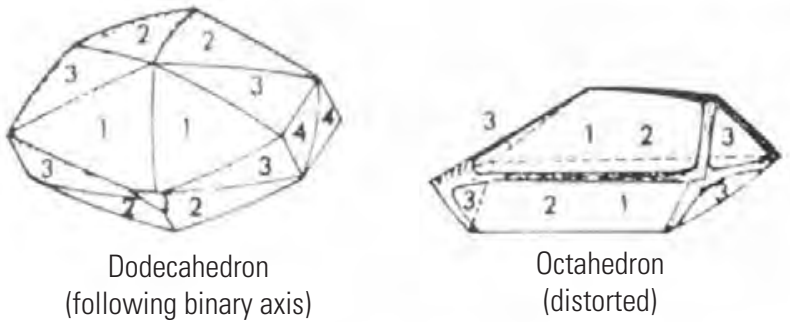

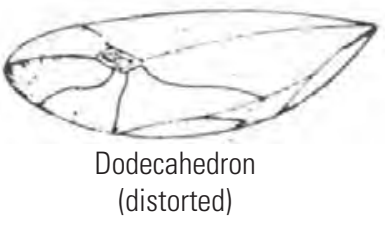


Depth, in meters

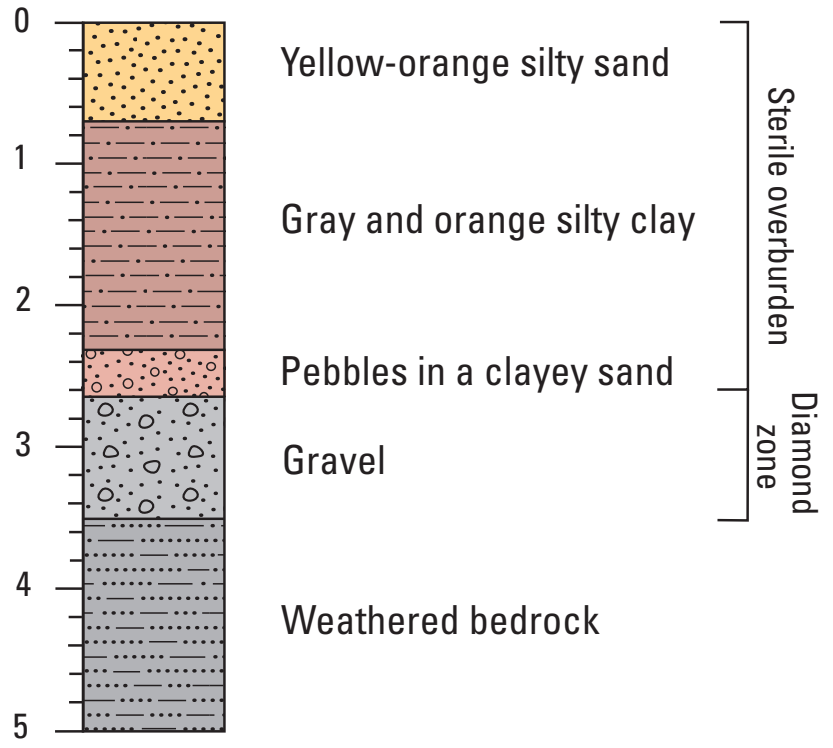

Figure 5. Sample profile of an artisanal mine site in Ghana illustrating the layering of gravels and overburden atop bedrock.

take into account these estimates, particularly if they refer to locations near the study area.

- Any previous work or studies completed on artisanal miners in the country, to include the numbers, movements, or long-term studies of trends in the ASM sector:

- Estimates concerning the number of active artisanal miners working in the diamonds sector is an important indicator of how many carats of diamonds a country is capable of producing. As the number of miners increases, production potential capabilities also increase. Estimates for production potential rely on other factors too-including the number of days miners work per year and gravel grade_-but the size of the workforce is a critical component.

- The tools, techniques, and methods employed by miners:

- The productivity of miners depends on several factors. Primarily, their productivity is related to the richness of the deposit and its accessibility, as defined by the geomorphic setting. However, the tools and techniques employed by individual miners or mining groups and cooperatives affect their productivity as well. Some miners may have access to earth-moving equipment and sorting machines, whereas others are relegated to using shovels and handmade sieves.

- The history of diamond mining in the country:

- When and where has industrial mining occurred? Are there available records on exploration, mining, and export licenses? Is artisanal mining legalized and defined in the Mining Code? Identifying the locations of previous mining activities can lead to the collection of valuable information, including data on the size, grade, and concentration of deposits (fig. 6).

All information with an associated geographic location can be entered into a digital database or spreadsheet, such as Microsoft Excel. In this form, the database should be easily transferable into a GIS, ensuring that the data can be viewed spatially in a mapping software.

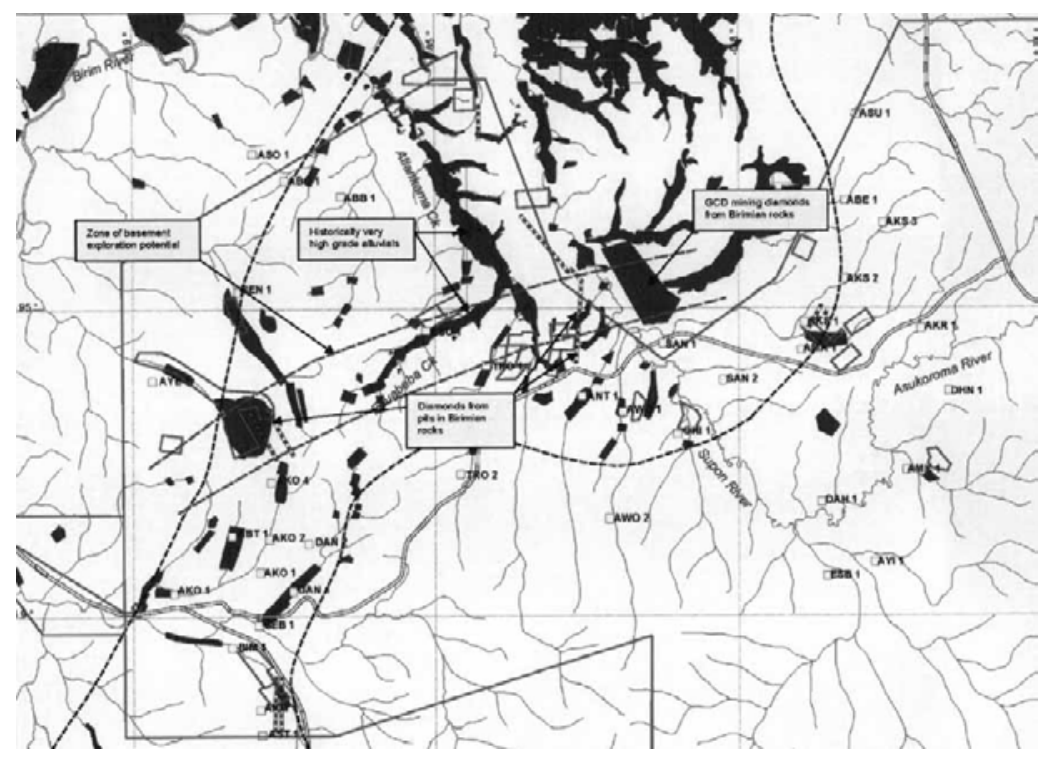

\begin{tabular}{|c|c|c|c|c|c|}
\hline SAMPLE & $\begin{array}{c}\text { SAMPLE } \\
\text { SIZE (bcm) } \\
\end{array}$ & $\begin{array}{c}\text { DIAMONDS } \\
\text { RECOVERED } \\
\end{array}$ & $\begin{array}{c}\text { TOTAL } \\
\text { CARATS }\end{array}$ & $\begin{array}{l}\text { GRADE } \\
\left(\mathrm{ct} / \mathrm{m}^{3}\right)\end{array}$ & $\begin{array}{l}\text { AVERAGE } \\
\text { SIZE (ct) }\end{array}$ \\
\hline AKO 1 & 17.7 & 72 & 1.98 & 0.11 & 0.028 \\
\hline $\mathrm{AKO} 2$ & 7.0 & 64 & 2.55 & 0.36 & 0.040 \\
\hline $\mathrm{AKO}_{3}$ & 7.4 & 21 & 0.89 & 0.12 & 0.042 \\
\hline AKO 4 & 8.0 & 46 & 2.00 & 0.25 & 0.043 \\
\hline SEB 1 & 12.4 & 18 & 0.91 & 0.07 & 0.051 \\
\hline DAN 1 & 12.3 & 104 & 2.98 & 0.24 & 0.029 \\
\hline DAN 2 & 7.0 & 45 & 1.80 & 0.26 & 0.040 \\
\hline SEN 1 & 11.8 & 96 & 4.4 & 0.37 & 0.046 \\
\hline $\mathrm{ABO} 1$ & 13.3 & 119 & 3.43 & 0.26 & 0.029 \\
\hline ASO 1 & 13.9 & 37 & 1.26 & 0.09 & 0.034 \\
\hline ESU 1 & 13.6 & 50 & 3.13 & 0.23 & 0.063 \\
\hline TRO 1 & 9.5 & 87 & 4.87 & 0.51 & 0.056 \\
\hline TRO 2 & 11.5 & 16 & 0.46 & 0.04 & 0.029 \\
\hline TRO 3 & 9.9 & 23 & 0.57 & 0.06 & 0.025 \\
\hline ATI I & 14.4 & 79 & 4.39 & 0.31 & 0.056 \\
\hline ANT 1 & 14.7 & 44 & 2.69 & 0.18 & 0.061 \\
\hline AWO 1 & 17.0 & 77 & 3.87 & 0.23 & 0.050 \\
\hline AWO 2 & 6.4 & 3 & 0.17 & 0.03 & 0.057 \\
\hline OHI 1 & 27.6 & 16 & 0.7 & 0.03 & 0.044 \\
\hline ESB I & 12.0 & 5 & 0.2 & 0.02 & 0.040 \\
\hline NWA 1 & 14.3 & 5 & 0.14 & 0.01 & 0.028 \\
\hline BIM I & 16.2 & 103 & 6.67 & 0.41 & 0.065 \\
\hline BIM 2 & 11.2 & 33 & 0.53 & 0.05 & 0.016 \\
\hline
\end{tabular}

Figure 6. Example of a concession location map with a corresponding table detailing grade and size information (from Calderwood and Ankrah, 2005). 


\section{Tool 1c: Identifying Stakeholders}

Commensurate with the scale of the assessment, researchers engage international, national, and (or) local stakeholders as participants in the research. Collaboration among industry, NGOs, and civil-society organizations assists with the collection and dissemination of data in a transparent manner that meets the interests of all involved parties. In order to establish relationships with relevant stakeholders, meetings are arranged to inform stakeholders of the research plans and goals.

Furthermore, these meetings are used to determine the roles of each stakeholder. Different levels of stakeholders include but are not limited to the following:

- International: The KP and its Working Groups-

- The Working Group of Diamond Experts (WGDE)

- The Working Group on Monitoring (WGM)

- The Working Group on Statistics (WGS)

- The Working Group on Artisanal and Alluvial Producuction (WGAAP)

- National: The host-country's minerals, geologic, or resource management agencies-

- Protocol Note: When meeting with the minerals or geologic agencies, the researcher may request an Ordre de Mission or similar document. This is an official letter, usually from the Ministry of Mines but in some cases other Ministries, such as Natural Resources, showing official government support and requesting the cooperation of regional or local entities. Multiple copies of this letter are brought into the field, to be left with the appropriate local authorities.

- Civil Society: NGOs working with artisanal miners in a local, regional, national, or even international context.

- Miners: Miners' unions, cooperatives.

- Local communities: Local community groups, which may or may not be organized into formal NGOs but may represent specific interests related to ASM and therefore can provide key information.

\section{Tool 2: Fieldwork Planning And Preparation}

The next phase following Project Planning is fieldwork planning and preparation. This is a critical component of the project and can influence the success of the fieldwork mission. This tool is outlined below in the following sections:
Identifying Field Sites, Logistical Preparation, Field Map Preparation, and Field Materials.

\section{Tool 2a: Identifying Field Sites}

Identification of field sites is a critical component of the field assessment preparation phase. Individual sites are identified, and a travel route between sites is planned. Among the considerations when planning which mine sites to visit and what route to take are the location of actively mined deposits, the condition of transportation infrastructure between sites, the availability of suitable vehicles, lodging accommodations along the route, available financial resources, the security situation in and around the sites, and the amount of time available for field visits. Following are several tools that can be used to identify field sites:

- The database of existing sites and diamond occurrences, compiled as part of the literature review.

- Working with in-country contacts such as the national minerals agency and NGOs targeting artisanal mining communities. Such contacts should have knowledge of the location of the most active sites in the country.

- Satellite imagery and (or) internet mapping resources, such as Google Earth, Bing Maps, or others, which can be used to locate current mining activities (fig. 7). A combination of historical and current imagery can be used to identify trends in mining activities and determine active versus inactive sites. When analyzing satellite imagery, it is important to understand the typical differences in appearance of active and inactive sites (fig. 8):

- Active mining pits have the appearance of a bright rim of reflective sandy material and nearby spoil material piles.

- Active pits have little or no water at the bottom.

- At inactive sites, the pits have typically filled with water, and there is no bright rim of reflective material.

- Inactive sites tend to show some degree of vegetation regrowth, unless the site was only recently abandoned.

- Large active pits in alluvial flats nearly always exhibit some degree of "benching" or organized sequential excavation. These benches are cut in a stepwise fashion, enabling deeper gravels to be exposed incrementally with less risk of sidewall collapse. However, many times the deposits are shallow enough that benches are not required. For example, benches are usually not present when only one or two miners are working a small pit or when the 
deposits are too deep for benching, in which case the miners use shaft and tunnel techniques.

- Pits with no benching are evidence of possible recent activity or a record of past activity.

- Generally, square pits eventually collapse in response to precipitation and groundwater fluctuations and begin to resemble roughly circular shapes.

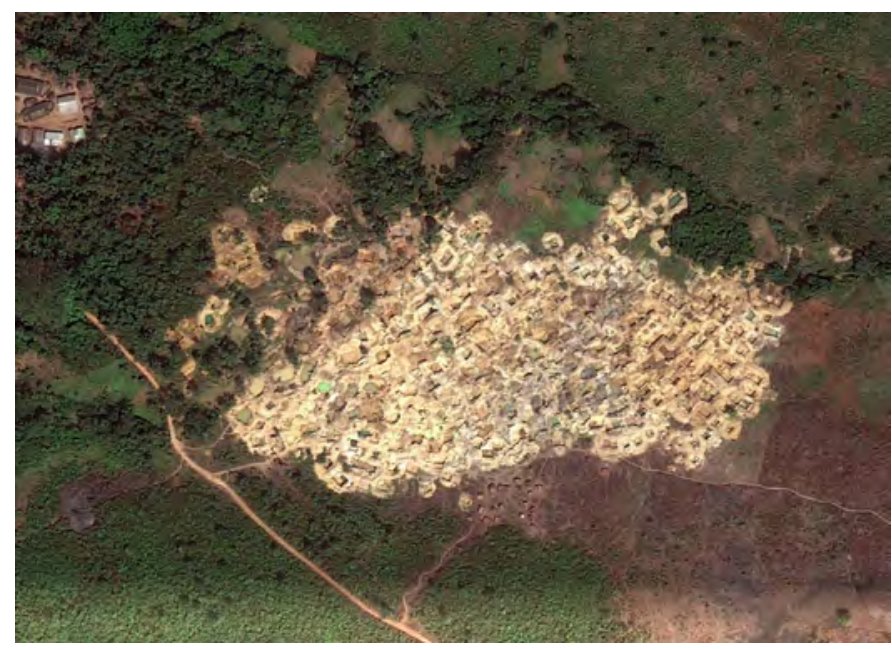

Figure 7. Example of an active artisanal diamond mining site, in the Coyah Prefecture of Guinea, identified via Google Earth.

\section{Tool 2b: Logistical Preparation}

Mine sites are typically remote, may be difficult to access, and may not be near a major town or village. As a result, many logistical preparations need to be made before embarking on the field mission, among which are the following:

- Securing access to suitable field vehicles and drivers; ideally, each field team should have at least two field vehicles, for safety and as backup in case of mechanical difficulties (fig. 9).

- Determining and securing the location of lodging accommodations in relation to the field sites (fig. 9).

- Determining the location of fuel and mechanical accommodations along the route. If none will be available, fuel supplies and spare parts must be purchased and brought into the field.

- Make plans to address any potential security risks. Will it be necessary to hire security? Contact local and international organizations as well as large international institutions that are operating in the country or study area, such as the United Nations or World Bank. Such organizations will have a good understanding of the security situation and knowledge of where to obtain security if needed. The Ministry of Mines may also have its own mining police or other form of security, which may assist with security planning and information.

- Identify and plan for the particular season in which the researchers will be in the field. Will fieldwork take place during the dry season or wet season?

- There are times during the dry season when mining activities are slowed because of a lack of water for washing and sorting the extracted gravels. In contrast, high water in the wet season usually prevents mining from taking place in most alluvial zones. To address these concerns, in some zones miners will extract gravel during the dry season, pile it along riverbanks, and then wash the gravels during the wet season. Therefore, if the goal of the project is to observe extraction activities, the dry season may be a better time for fieldwork. However, if the goal is to observe washing activities, fieldwork during the rainy season may be ideal, depending on the techniques employed at the study sites. Careful research must be done to determine the timing of fieldwork.

\section{Tool 2c: Field Map Preparation}

Topographic and geologic field maps are critical components of field studies. These maps assist researchers in identifying locations where mining activities may be occurring by revealing terrain upstream or downstream of known deposits, and they are indispensable for navigating unfamiliar terrain.

Before commencing fieldwork, acquire or develop topographic and geologic base maps for use in the field (fig. 10). These maps include the following data layers:

- Elevation contours.

- Rivers and streams, with as many labeled as possible.

- Towns and villages, with as many labeled as possible.

- Primary and secondary roads.

- Known diamond deposits and kimberlites.

- The preplanned field sites that will be visited during fieldwork.

- As a background layer, either a digital elevation model, underlying geology layer, or a satellite image of the area can be used. A satellite image base is ideal, if available, because larger mine sites can be seen in medium- to high-resolution imagery.

If the research team has a GIS capability or experience with digital mapping applications, topographic base maps can be developed and customized to the specific fieldwork 


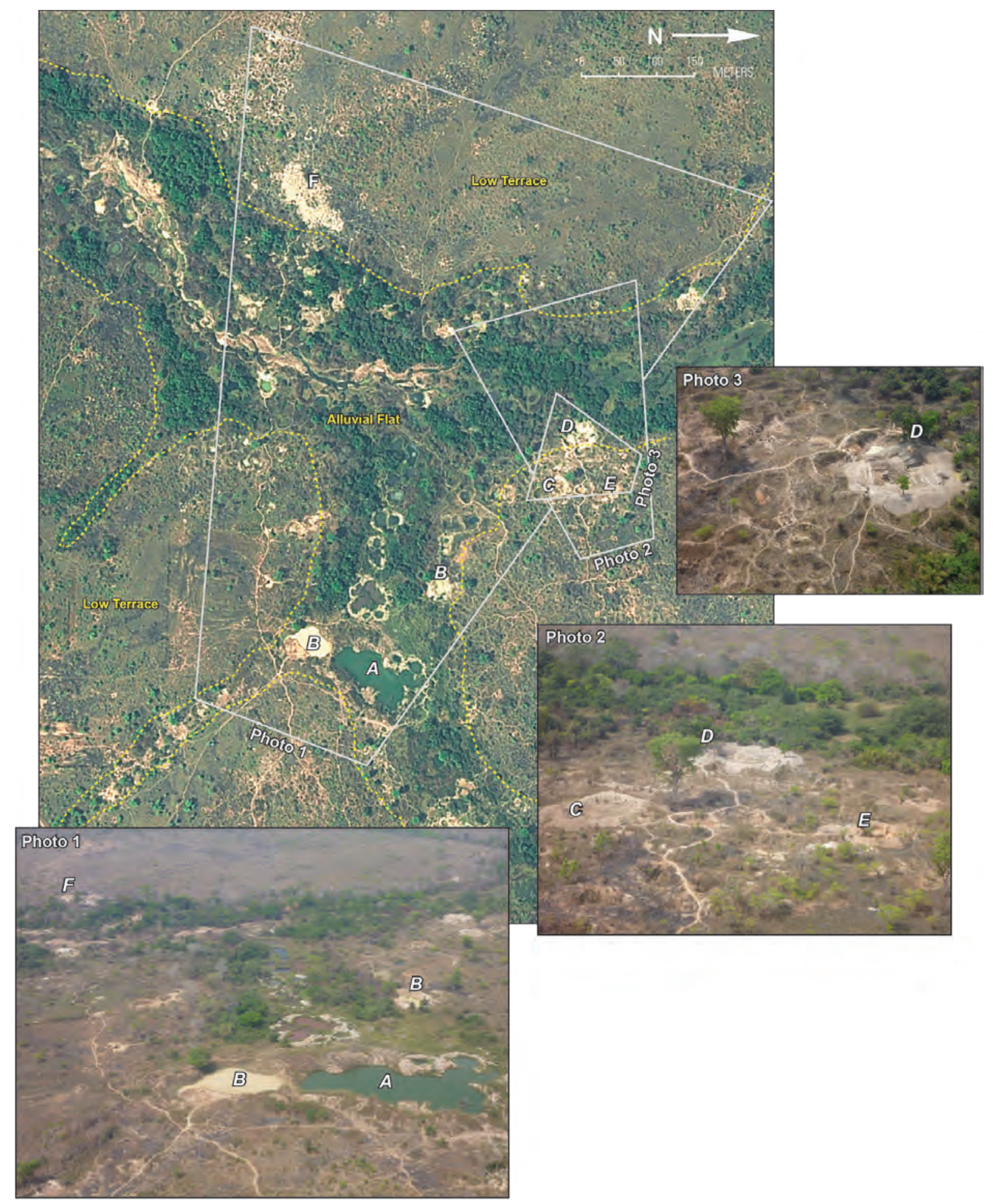

Figure 8. A comparison of oblique aerial photography and a Worldview-2 satellite image. The Worldview-2 image, collected on February 3, 2012, shows the intense mining activities of artisanal miners in a flood plain in Séguéla, Côte d'Ivoire. Oblique photography collected at the same site one week prior, on January 27,2012 , shows a detailed view of the active and inactive mining pits. $A$, Large inactive mining pit, which has now filled with water. $B$, Two previously mined pits that have filled with sedimented water, indicating that they were recently used for washing and sorting gravel. $C$, A recently abandoned pit with eroded headwalls that has not yet filled with water, indicating recent but completed activity. $D$ and $E$, Large active mining pits with the headwalls visible where miners are in the process of excavating. The particularly bright reflectance of the recently removed spoil materials surrounding the pits in the satellite image is further evidence of the pits' activity. $F$, A cluster of small exploration pits in the low terrace geomorphic zone (from Chirico and Malpeli, 2013). 
mission. If this is not an option, the team should try to acquire maps through the host country's mapping agency or supplier of geologic maps, the minerals and (or) geologic agency,

NGOs, or foreign government mineral or geologic agencies that have previously worked in the study area. Multiple maps may need to be acqired to obtain all of the necessary data layers.

Figure 9. Example of a typical
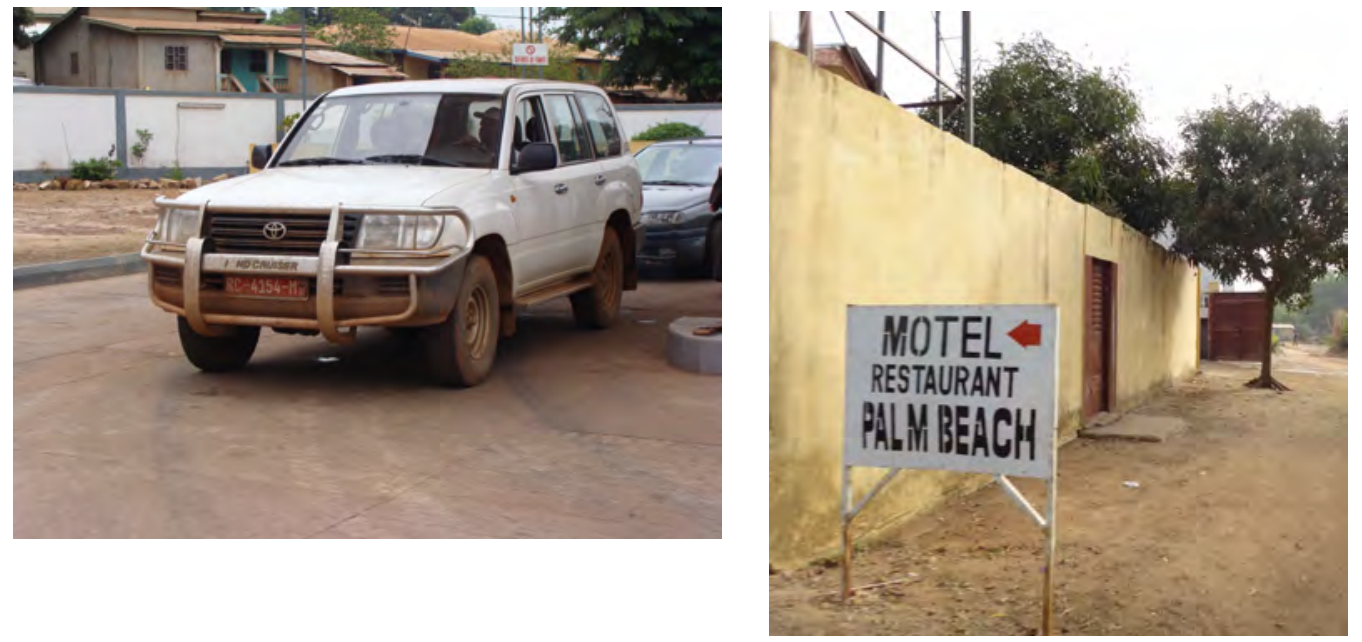
accomodations.

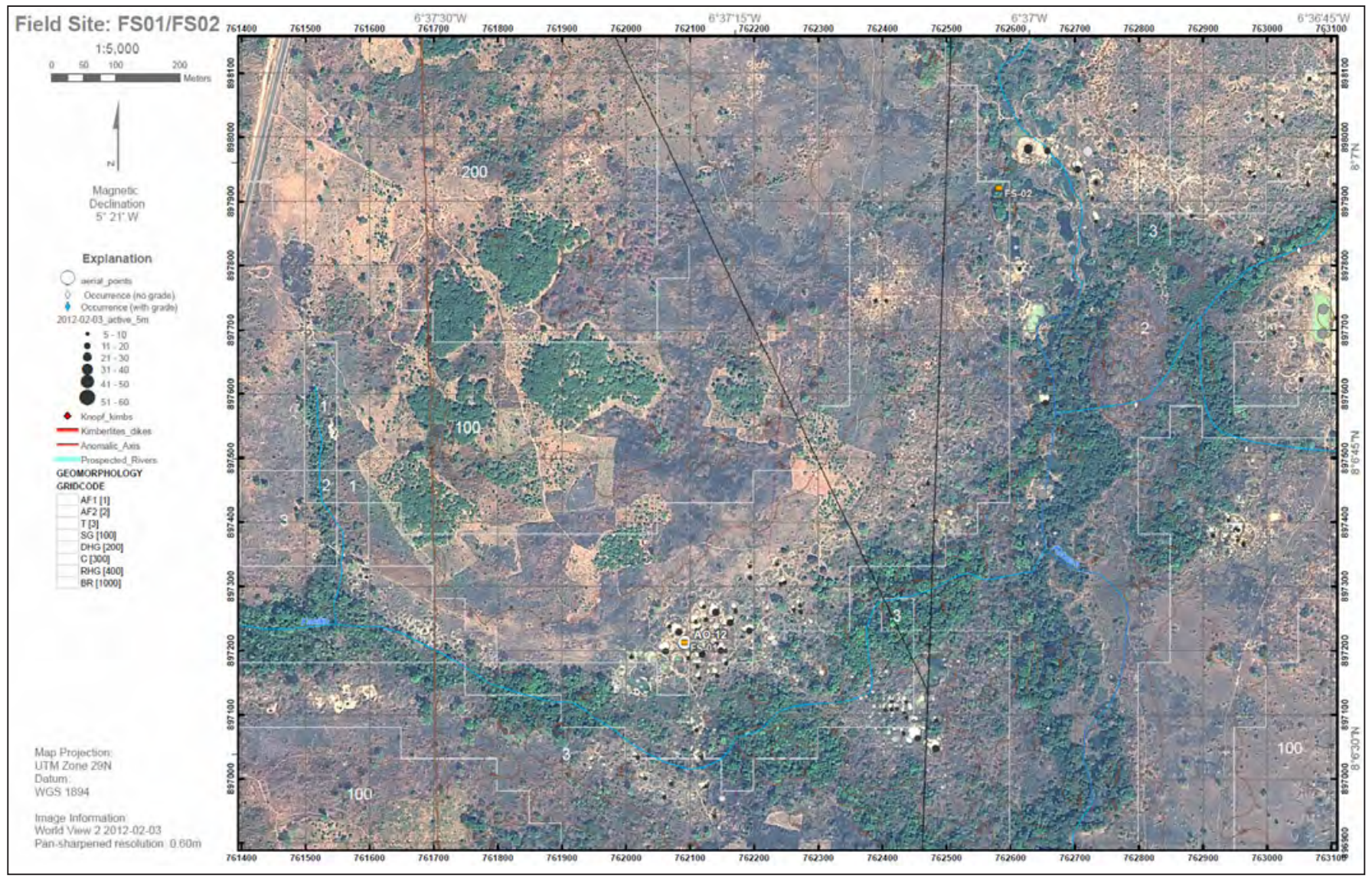

Figure 10. Example of a base map with a satellite image background. 


\section{Tool 2d: Field Materials}

In addition to base maps, various other field materials are useful - if not essential — for fieldwork:

- Enough copies of the field data-collection sheets (appendixes 1-3) so that one sheet can be completed at each site. Bring extra, in case you visit more sites than were planned for.

- A Global Positioning System (GPS) unit, so that accurate geographic coordinates and elevation data can be recorded at each site.

- A digital camera, to be used to take multiple photographs of each site, documenting the mine pits and mining activities.

- A compass, to orient the user's location on the base map and assist with documenting location descriptions.

- Multiple copies of all permission documentation, such as an Ordre de Mission, issued by any government authority.

- A tape measure, to measure pits and sketch geomorphic profiles.

- A notebook, preferably with waterproof paper, to write down any additional observations that are not included in the field data sheets.

- A small ruler, which can be used to measure diamonds and grain sizes.

- Field sample bags for sediment sample collection.

- Mosquito nets and insect repellent.

- Sunhat and good boots for walking in the mine terrain.

- Food, water, and basic provisions for travel in remote areas.

- Phone charger and batteries.

- Cash for buying things, plus small tokens (cigarettes, pens, etc.) to give to miners and others in the community.

\section{Tool 3: Fieldwork}

Tools 1 and 2 guide the researcher through the planning and preparation stages of the project. Upon completion of these steps, the researchers will have developed a solid foundation from which they can launch a successful fieldwork campaign. Tool 3 describes the elements of performing fieldwork and details the different data-collection methods used in the field. This tool is divided into local protocol visits (tool 3a) and the data-collection methodology (tool 3b).

The data-collection methodology is further subdivided into three categories, each representing a distinct datacollection technique: direct observation, face-to-face interviews, and the collection of photographs. Each category serves to collect different types of data, which, when analyzed together, provide detailed insight into the nature and condition of the mining sector in the study area. This unique methodology focuses on the collection and integration of both physical-science and social-science data at the mine sites so that a comprehensive understanding of the artisanal mining sector can be achieved.

In order to ensure the collection of all necessary geologic, geomorphic, and social-science data, a comprehensive field data sheet has been developed and is used to collect data at each visited mine site. The field sheet is separated into three tiers: Tier 1, the Mine Site data sheet; tier 2, the Mine Manager data sheet; and tier 3, the Miner Life data sheet. The field data sheets include sections where the researcher records measurements and observations related to particular site characteristics, as well as sections filled out as the researcher conducts face-to-face interviews with miners at the site. Because of the nature of the field data sheets, it is essential that they be completed at the mine site itself rather than at the local community. Through the use of these data sheets, descriptive data are collected to provide a snapshot of artisanal mining activities during the time of the visit, allowing for the estimation of how certain parameters within the sector will evolve over time. The field data sheets are included in this document as appendixes 1,2 , and 3 .

\section{Tool 3a: Local Protocol Visits}

Specific protocol is followed to engage local officials and inform them of the nature and goal of the field visits (fig. 11). These visits may occur within any of the local-level administrative boundaries (prefecture, subprefecture, county, or other) where fieldwork will take place. Protocol visits allow the researcher to explain the purpose and objectives of the project to officials throughout different levels of administration. If the researcher obtained any permission documentation (described above in Tool 1c) while meeting with the minerals or geologic agency in the capital, a copy may be given to the local official. As part of the project explanation, the researcher can educate authorities on the KP and the importance of its mission. These visits provide an opportunity for the researcher to increase stakeholder knowledge and cooperation and enlist the support of local authorities in the monitoring of artisanal mining activities. It also provides an opportunity to listen to local officials and gain an understanding of their views of the ASM activities, issues, and challenges.

This tool is used throughout the course of fieldwork, as researchers travel across local-level administrative borders. If each field site is within a different administrative boundary, 
Figure 11. Photos of a local prefecture visit: Elders at a mine site (left) and a local mining office (right). Photos by Mamadou Diaby, Centre du Commerce International pour le Développement.
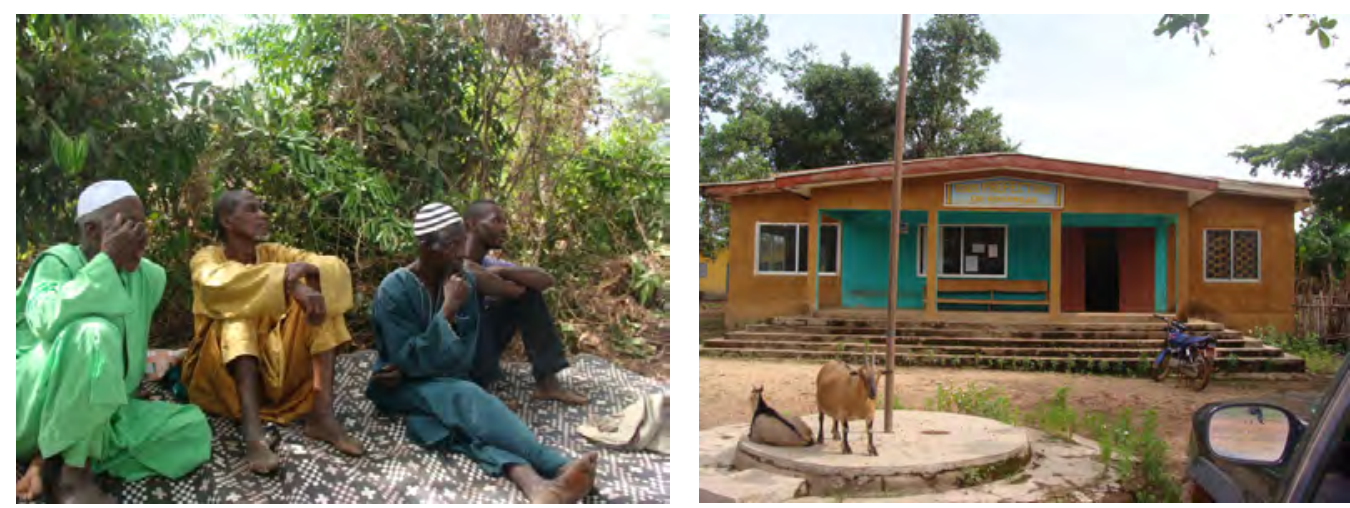

then a separate local protocol visit is completed before fieldwork begins at each site. If field sites happen to be grouped within administrative boundaries, a protocol visit will be conducted only upon entering a new boundary.

\section{Tool 3b: Data-Collection Method 1-Direct Observations}

Direct observations of ASM activities are an important component of the data-collection methodology. The Mine Site data sheet is used to record observations at each visited site (appendix 1). Because of the nature of the type of data that must be collected, it is essential that the data sheet be completed at the mine site itself, rather than at the local community. The goal of the Mine Site data sheet is to collect information on the following:

- The geographic location of the site, including its coordinates and the distance to the nearest town and river.

- The date on which the observations were made, to determine the seasonal period both from a mining and agricultural perspective.

- The number of men, women, and children working at the site.

- The types of tools used-

- Are the tools artisanal in nature?

- Are mechanized equipment, such as backhoes, present at the site?

- The types of jobs performed by men, women, and children.

- Mineral extraction and washing techniques.

- The environmental conditions around the site-

- What is the vegetation type found at the site?

- Is there evidence of deforestation?

- Has a river channel — or other water source — been diverted?
- Are there threatened or endangered species endemic to the area near the mine site?

- Have secondary human settlements been established near the mine site?

- Geologic observations-

-What is the composition of the bedrock?

- Are there any outcrops?

- What geologic features are visible?

- The geomorphic expression of the site: active channel, alluvial flat, or terrace.

- A geomorphic profile of one or more pits at the site, detailing the depths and characteristics of the overburden layers and gravel layers (fig. 12).

Obtaining this type of data will assist with analyzing a site's characteristics. Many conclusions can be drawn by examining such data, including the following:

- The intensity of mining activities at the site, based on the number of miners, the size of the site, and the tools used.

- An estimate of the current and future environmental conditions in and around the mine site.

- Assessments as to the economic potential of the deposits, which can be made by profiling the geomorphic and geologic expression of the site. Geomorphology influences the location and grade of deposits, information which is crucial in determining their economic potential and thus the likelihood of whether the mining of a particular zone is foreseeably profitable.

- Gender roles at the mine site can be determined by examining the ratio of male to female workers and the types of jobs performed by each. 


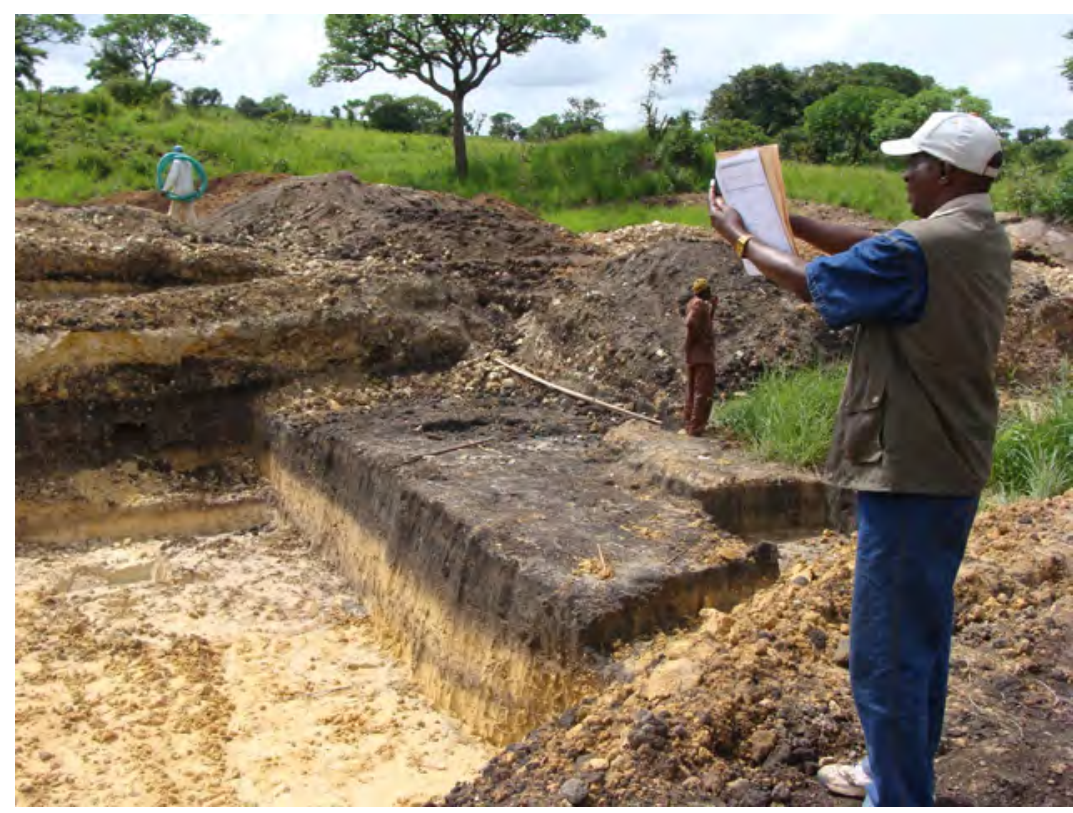

Depth,

in meters

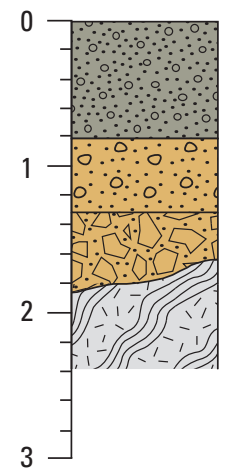

Dark gray silt with pebbles

Gravel in a yellow clay matrix

Sandstone clasts and clay

Upper Proterozoic mafic gneiss

Figure 12. Example of a researcher collecting data in the field (left) and a geomorphic profile (right). Photo by Mamadou Diaby, Centre du Commerce International pour le Développement.

\section{Tool 3c: Data-Collection Method 2-Face-to- Face Interviews}

Both the Mine Manager and Miner Life data sheets require the researcher to conduct face-to-face interviews to gather data. The goal is to conduct one interview with the mine manager and a set of Miner Life interviews with miners at each mine site. If possible, multiple members of the fieldwork team can each interview managers and miners, increasing the number of interviews conducted, without slowing down the data-collection process. The researcher should begin by explaining the purpose of the interview to the individual or group of miners, and make clear that they need not feel obligated to participate or to respond to all questions. It is also important to inform participants that although their names may be recorded, their responses will be kept anonymous in any future disseminated documentation of the interviews. Their right to confidentiality should be explicitly stated, and the interviewer must obtain their consent prior to beginning the process. This is a crucial step when interviewing artisanal miners, particularly in situations where the activity is informal or illegal, which may lead to fears of government intervention.

Interviews at the mine site are frequently conducted in a group setting. As the research team approaches and begins speaking with a miner or mine manager, a group of interested miners typically forms. Generally in this group setting, answers resemble a consensus of the group's experience and provide an informative overview of the ASM population at the site; however, researchers should also attempt to select individual miners from the group with which to conduct separate, individual interviews. These interview responses can then be compared to the responses of the group and other individual miners. As the research team moves around the site, other miners may be asked subsets of questions to gather more data and compare responses, to ensure that a complete understanding of the mining activities of the site are achieved. If there are discrepancies noted in the answers to questions, it is often enlightening to ask the same questions in a different manner and see how the answers may evolve. In many cases, responses from miners at a particular site are similar and additional interviews yield little new information, yet multiple interviews are critical to ensure that proper sampling techniques are followed.

\section{The Mine Manager Interview}

The goal of the Mine Manager data sheet is to interview a site's manager to collect data related to how the site is run and operated (appendix 2). The mine manager is asked a mixture of closed and open-ended questions. The focus of this survey is the characteristics of the diamonds found at the site, the operational history of the mine, the economics, and the legal history of the mine. Mine managers may not be willing to provide direct answers to all questions or to be transparent about the activities at the mine site. It is important to ask the manager if they collect production records and if they are willing to share those with the interviewer to assist with collecting data on the productivity of the mine. As with all interviews, it is important to remember that individual interviews cannot be relied upon to be the sole source of information of activities at ASM sites. During the Mine Manager interview, data are collected on the following:

- The history of activity at the mine and the seasonality of activity. 
- The group structure at the site, including the structure and organization of digging teams.

- The way in which workers are paid.

- The characteristics of the diamonds found at the site, including the most frequently found size, color, shape, and quality of the diamonds.

- The way in which production is recorded and how the diamonds are valued.

- Whether the site is legal and (or) has a permit, and if so, who owns the permit.

The data collected through interviewing the mine manager can be used to make conclusions about-

- The extent of unregistered mining activities occurring in the country. What percentage of the miners and mine sites have a permit? If the country has a program implemented to register miners, the success of the program can be measured by using these data.

- The number of months during which the mine is operational, information that assists with determining the production level of the site.

- The average grade, size, color, and quality of the diamonds, inference about which is important in understanding the economic potential of a site because these characteristics determine the value of the diamonds.

\section{The Miner Life Interview}

The goal of the Miner Life data sheet is to conduct a detailed structured interview with a representative sample of randomly selected miners who have agreed to be interviewed (appendix 3). In each case, the interviewee is asked a variety of closed and open-ended questions. The research team should attempt to collect at least one Miner Life interview at each field site, though if possible they may interview multiple miners.

In general, the greater the sample population, the greater the accuracy of the results. However, extensive interviewing is not always practical or feasible, given the available resources (time, money, staff). In quantitative research, the sample size depends on the desired accuracy and the size of the total population. Ideally, a large enough sample is surveyed to achieve an accuracy of 95 percent (in other words, the researcher is 95 percent confident that the results do not vary by more than 5 percentage points). However, the resources required to attain this level of confidence are frequently not available to the researcher, and a lower level of confidence may be sufficient (Eftimie and others, 2012). The surveys conducted during this type of assessment are not intended to represent an extensive and comprehensive collection of data; rather, the goal is to provide insight into the important factors influencing the ASM population and to make comparisons of responses collected at a variety of sites.

The number of interviews that the research team is capable of collecting depends on several variables. First, the goal of the research determines in large part the amount of time researchers are able to spend at each mine site and thus the number of interviews they can collect. For example, if the goal of the study is to complete a national-scale assessment of artisanal mining sites, then it is likely that a large proportion of time will be spent traveling from site to site, thus reducing the amount of time available to be spent at each site. In such cases, the research team may be able to conduct only one or two Miner Life interviews per site. However, if the goal is to complete a local-scale study, less time will likely be spent traveling and more time can be spent at each site, resulting in a greater number of interviews. The second influential factor concerns the size of the mine site. At a small site with 5 to 10 miners, interviewing 100 percent of the population may be possible; at a large site with 500 or more miners, however, attempting to interview 100 percent of the population is not realistic. At such sites, researchers may choose to interview miners using a focus group format, in which one or more groups of 10-20 miners are interviewed collectively and the answers agreed upon by the group are recorded. The implementation of this method results in an overview of the ASM population as a whole at the site. A combined method of individual interviews and focus group interviews may also be used.

During the Miner Life interview data are collected on the following characteristics of miners:

- Their age and gender.

- The number of years they have worked in the sector.

- The number of hours they work per day and the number of months they work per year.

- Whether they are involved in a secondary livelihood, such as agriculture.

- How often they find diamonds, and the size of the biggest diamond they have ever found.

- How, where, and to whom they sell the diamonds they find.

- Where they are originally from, and other mines where they have worked.

- Their reasons and motivations for mining.

The data collected in the Miner Life data sheet from the multiple field sites can be compared and contrasted and used to assess the condition and characteristics of the artisanal miner population at each site and within the larger study area. Information collected through the interviewing process will help to answer important questions related to ASM activities, such as the following: 
- What drivers (economic, social) are causing people to move into the artisanal diamond mining sector?

- How transitory is the artisanal miner population? Have the majority of miners interviewed worked at multiple sites?

- How willing are the miners to migrate to other sites, and for what reasons?

- The success of the miners: Do they find diamonds often? Are they engaged in supplementary livelihood activities in addition to mining?

\section{Tool 3d: Data-Collection Method 3-The Collection of Photographs}

In addition to the use of field sheets, photographs taken at the mine site constitue an important component of the data-collection process. Multiple photos are taken at each site and are attributed with GPS coordinates to define their exact location. The advent of GPS-enabled digital cameras and cellphones has assisted with this process by automatically geographically referencing photos. These photos can be used to make both qualitative and quantitative assessments of the mine site upon return from the field. General overview photos of a site can depict details such as the general activity level, extraction and processing tools and techniques, and information on gender roles. In addition, multiple photos are typically taken of one or more active pits to record the dimensions and geomorphic nature of the pit in detail (fig. 13). The recent development of software technologies that produce Structure from Motion (SFM), such as Bundler and Photosynth, have the ability to merge multiple photos of a location and produce three-dimensional digital visualizations of mine sites, which can be quantitatively analyzed. The ways in which

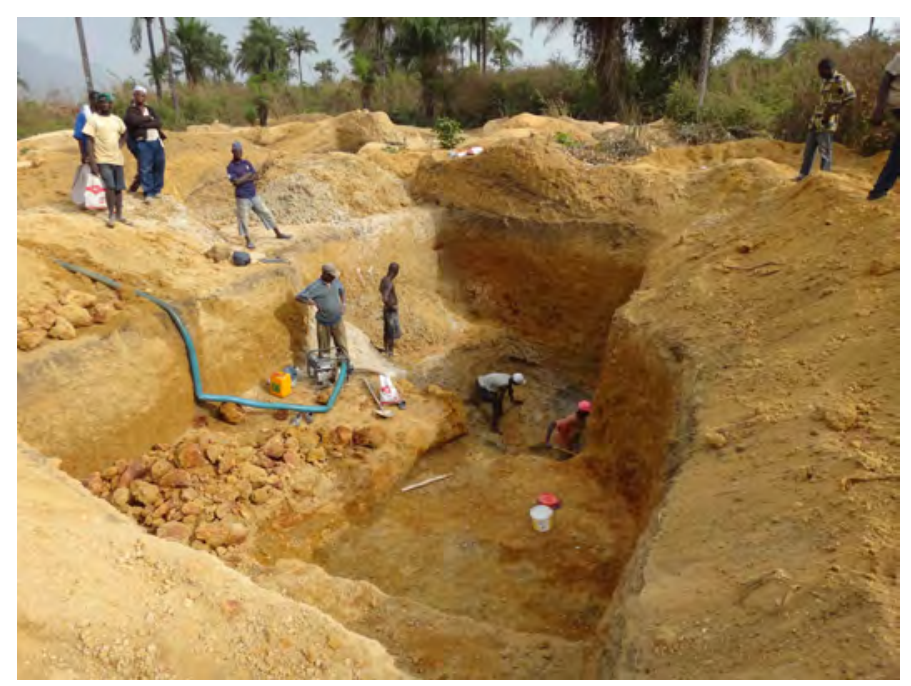

photographs can be used to document site characteristics continues to grow.

\section{Tool 4: Summarizing And Reporting Fieldwork Results}

Upon the conclusion of fieldwork, a report summarizing the results of the field visits is written and disseminated to the involved stakeholders. The goal of this report is to provide a synopsis of what happened in the field - not necessarily an indepth analysis of all of the collected data. The full assessment will be written at a later stage and will incorporate the in-depth data analysis component. It is important to write the summary report immediately after completing fieldwork so that the stakeholders are made aware of the progress of the project and remain invested in its success. Below is a suggested outline for a summary report:

1. Introduction

a. State the purpose of the fieldwork.

b. Acknowledge those who assisted with the project, particularly government authorities and officials.

c. Introduce the fieldwork mission.

i. When was fieldwork done

ii. Where was fieldwork done

2. Study Area

a. Give a brief overview of the geographic and geologic nature of the study area.

b. Include a map showing the location of the sites visited during fieldwork. If a map cannot be created,

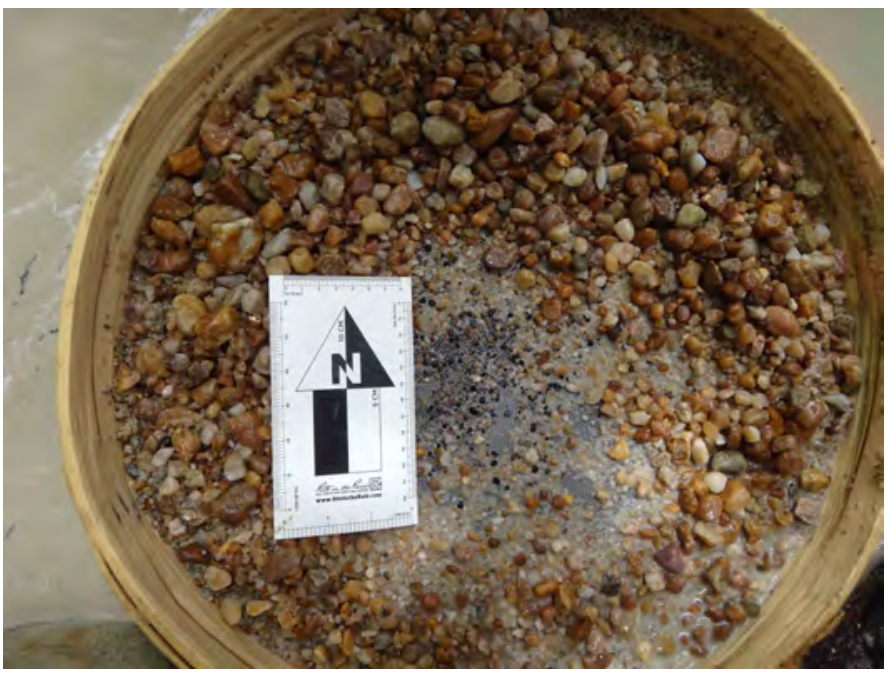

Figure 13. Examples of typical photos taken while doing fieldwork at a mine site. 
include a table listing each site and its associated geographic coordinates.

3. Methodology

a. Explain the methodology used to collect field data.

i. Direct observations

ii. Face-to-face interviews

1. Summarize the results in a manner that maintains the anonymity of the individual miners and adheres to the confidentiality agreement.

iii. Photographs

4. Results

a. Summarize the data collected at each site. Include basic information such as the name of the site, the size of the site, the number of miners, and the geologic and geomorphic expression. Do this for each site. Include a photograph of each site.

5. Discussion

a. What types of analysis will be performed on the data?

b. What is the research plan for carrying out the remaining phases of the project?

c. What will the end product be?

\section{Guinea: A Case Study}

The implementation of a multistakeholder approach for field data gathering is an important step towards ensuring that the necessary physical-science and social-science data are collected transparently and that the needs of all parties involved - international industry, national government, and civil society - are addressed. A model was developed in which members of the host country's mining ministry and civilsociety organizations collaborate in the collection of field data and receive international support from the KP. This model was implemented in the assessment of Guinea's artisanally mined diamond deposits. (For more details on this assessment, see Chirico and others, 2012.)

\section{Trainings}

The tripartite team was composed of representatives from Guinea's Ministry of Mines (MMG) and the civil-society organization Centre du Commerce International pour le Développement (CECIDE), working with the U.S. Geological Survey (USGS). Before going into the field, the team of representatives were trained by technical experts from the USGS in fieldwork methods, the use of handheld GPS devices, and filling out field data sheets. This training, which took place in June 2011, included a visit to two artisanal diamond mining sites during which data-collection techniques were practiced and refined by the representatives. In March 2012, a joint MMG-CECIDE team completed fieldwork at six mine sites. Later that month, a representative from the USGS returned to Guinea and completed fieldwork jointly with the MMGCECIDE team at seven additional sites as a followup, in-thefield training.

\section{Fieldwork Implementation}

As a result of the tripartite data-collection effort, an additional 22 field sites were visited by the MMG-CECIDE team, doubling the number of sites that had been visited by the USGS and bringing the total number of visited sites to 40. Sites were visited within the Forécariah, Coyah, Kindia, Télimélé, Kissidougou, Macenta, and Kérouané Prefectures. Seventeen of the 22 sites visited by the MMG-CECIDE team were in the intensively mined Macenta and Kérouané Prefectures. These prefectures had not been previously visited by the USGS, owing to logistical difficulties associated with accessing these sites, and therefore the data collected by the MMG-CECIDE team were a valuable addition without which a comprehensive understanding of Guinea's diamond deposits could not have been achieved. At each of the 22 additional sites, the Mine Site, Mine Manager, and Miner Life field sheets were filled out by each team member. The data collected by the MMG-CECIDE team was sent to the USGS by CECIDE, in both hardcopy and digital formats.

\section{Results}

Previous to this data-collection effort, no comprehensive assessment documenting the geologic nature of Guinea's diamond deposits and ASM activity at the country scale had been produced. The type of data collected following this methodology bridges the ever-present physical- and social-science barrier by providing both geologic and geomorphic information about the deposits, in addition to social, cultural, economic, and demographic data related to the miners who work the deposits. Several site-specific geologic and geomorphic studies of particular diamond deposits have been carried out; however, these were done at a small-scale, and the results could not be extrapolated far beyond the study sites themselves. The use of a tripartite team allowed for a large amount of data to be collected in an efficient and timely manner.

Artisanal diamond mining is a highly dynamic sector, owing to the finite nature of the resource and the transitory nature of miners. Diamond deposits inevitably are mined out, at which time artisanal miners are forced to either migrate to a new deposit location or leave the sector. Fluctuating commodity prices can result in miners leaving the diamond sector to 
mine a commodity with a higher market value, or, conversely, lead to a rapid increase in the number of diamond miners if prices change in the favor of diamonds. As a result of such frequent changes, it is necessary to continually collect data and monitor the diamond mining activities. Partnering with in-country agencies is the most efficient method for repeated data collection, because these partners can most easily access the deposits in question. Teams can be mobilized quickly to visit sites and provide an update of the current situation on the ground.

\section{Challenges}

Although tripartite collaborative data collection can be implemented successfully, it is not without its challenges. A number of institutional and logistical challenges can arise that may need to be addressed and overcome for effective application of the toolkit and project execution. First, the participation of host-country governments and civil-society organizations may be limited by financial and staffing restrictions. Furthermore, whereas team members are trained in field data collection techniques prior to the commencement of fieldwork, employee turnover can lead to the loss of trained representatives. Tension may also arise between government agencies and civil-society organizations, making it necessary to maintain continuous communication among various partners throughout the project planning stage, to ensure that any such concerns are addressed. Finally, even though incountry team members have easier access to field sites, certain logistical challenges are unavoidable. Poor weather, bad roads, vehicle and hotel accommodations, and security issues are all concerns which can prevent successful data collection and place financial strain on the project.

\section{Conclusion}

The Guinea case study demonstrates that the partnering of individuals representing the unique interests of industry, national government, and civil society to collect data on Guinea's alluvial diamond deposits is a successful approach for evaluating and monitoring the sector. Although not devoid of challenges, the application of this method, in partnership with multiple stakeholders, nonetheless resulted in the acquisition of invaluable data on the diamond deposits and current mining activities taking place within Guinea's diamond mining zones. The data collected by the tripartite team were incorporated into a comprehensive assessment of Guinea's alluvial diamond deposits, the most up-to-date and inclusive assessment of its kind. In the case of Guinea, a link has been established between industry, national government, and civil society that should be maintained to ensure that data-collection efforts continue so that changes that may take place within the country's diamond sector can be accounted for.

\section{References Cited}

Bardet, M.G., 1974, Géologie du diamant, gisements de diamants d'Afrique: Bureau de Recherches Géologiques et Minières Memoir, v. 2, no. 83, 223 p.

Barthélémy, Francis; Eberlé, J.M.; Duguey, E.; Jézéquel, P.; Husson, Y.; Moumpossa, R.; and Boutin, P., 2006, Republic of the Congo, diamond potential, production capacity, and the Kimberley Process - Final Report: Bureau de Recherches Géologiques et Minières, RC-54589-EN, 99 p.

Calderwood, Mark, and Ankrah, C.A., 2005, Annual reportOsenase reconnaissance licence RL5/12 for Leo Shield Exploration (GH) Ltd: Leo Shield Exploration (Ghana) Ltd., $32 \mathrm{p}$.

Chirico, P.G.; Barthélémy, Francis; and Koné, Fatiaga, 2010, Alluvial diamond resource potential and production capacity assessment of Mali: U.S. Geological Survey Scientific Investigations Report 2010-5044, 23 p.

Chirico, P.G.; Barthélémy, Francis; and Ngbokoto, F.A., 2010, Alluvial diamond resource potential and production capacity assessment of the Central African Republic: U.S. Geological Survey Scientific Investigations Report 2010-5043, 22 p.

Chirico, P.G., and Malpeli, K.C., 2013, Reconnaissance investigation of the rough diamond resource potential and production capacity of Côte d'Ivoire: U.S. Geological Survey Scientific Investigations Report 2013-5185, 46 p.

Chirico, P.G.; Malpeli, K.C.; Anum, Solomon; and Phillips, E.C., 2010, Alluvial diamond resource potential and production capacity assessment of Ghana: U.S. Geological Survey Scientific Investigations Report 2010-5045, 25 p.

Chirico, P.G.; Malpeli, K.C.; Van Bockstael, Mark; Diaby, Mamadou; Cissé, Kabinet; Diallo, T.A.; and Sano, Mahmoud, 2012, Alluvial diamond resource potential and production capacity assessment of Guinea: U.S. Geological Survey Scientific Investigations Report 2012-5256, 59 p.

Eftimie, A., Heller, K., Strongman, J., Hinton, J., Lahiri-Dutt, K., and Mutemeri, N., 2012, Gender dimensions of Artisanal and Small-Scale Mining-A rapid assessment toolkit: The World Bank Group's Oil, Gas, and Mining Unit, $142 \mathrm{p}$.

Erlich, E.I., and Hausel, W.D., 2002, Diamond depositsOrigin, exploration, and history of discovery: Littleton, Colo., Society for Mining, Metallurgy, and Exploration, p. 93.

Hall, A.M., Thomas, M.F., Thorp, M.B., 1985, Late Quaternary alluvial placer development in the humid tropics-The case of the Birim Diamond Placer, Ghana: Journal of the Geological Society, v. 142, p. 777-787. 
Hinton, J., and Hollestelle, M.R., 2012, Methodological toolkit for baseline assessments and response strategies to artisanal and small-scale mining in protected areas and critical ecosystems: Artisanal and Small-Scale Mining in and Around Protected Areas and Critical Ecosystems Project (ASMPACE), 94 p.

Marshall, T.R., and Baxter-Brown, R., 1995, Basic principles of alluvial diamond exploration: Journal of Geochemical Exploration, v. 53, p. 277-292.
Neuendorf, K.K.E., Mehl, J.P., Jr., and Jackson, J.A., 2005, Glossary of geology (5th ed.): Alexandria, Va., American Geological Institute, $779 \mathrm{p}$.

Noetstaller, Richard; Heemskerk, Marieke; Hruschka, Felix; and Drechsler, Bernd, 2004, Program for improvements to the profiling of artisanal and small-scale mining activities in Africa and the implementation of baseline surveys-Final report: Communities and Small-Scale Mining (CASM), $160 \mathrm{p}$. 


\section{Appendix 1. Mine Site Data Sheet}

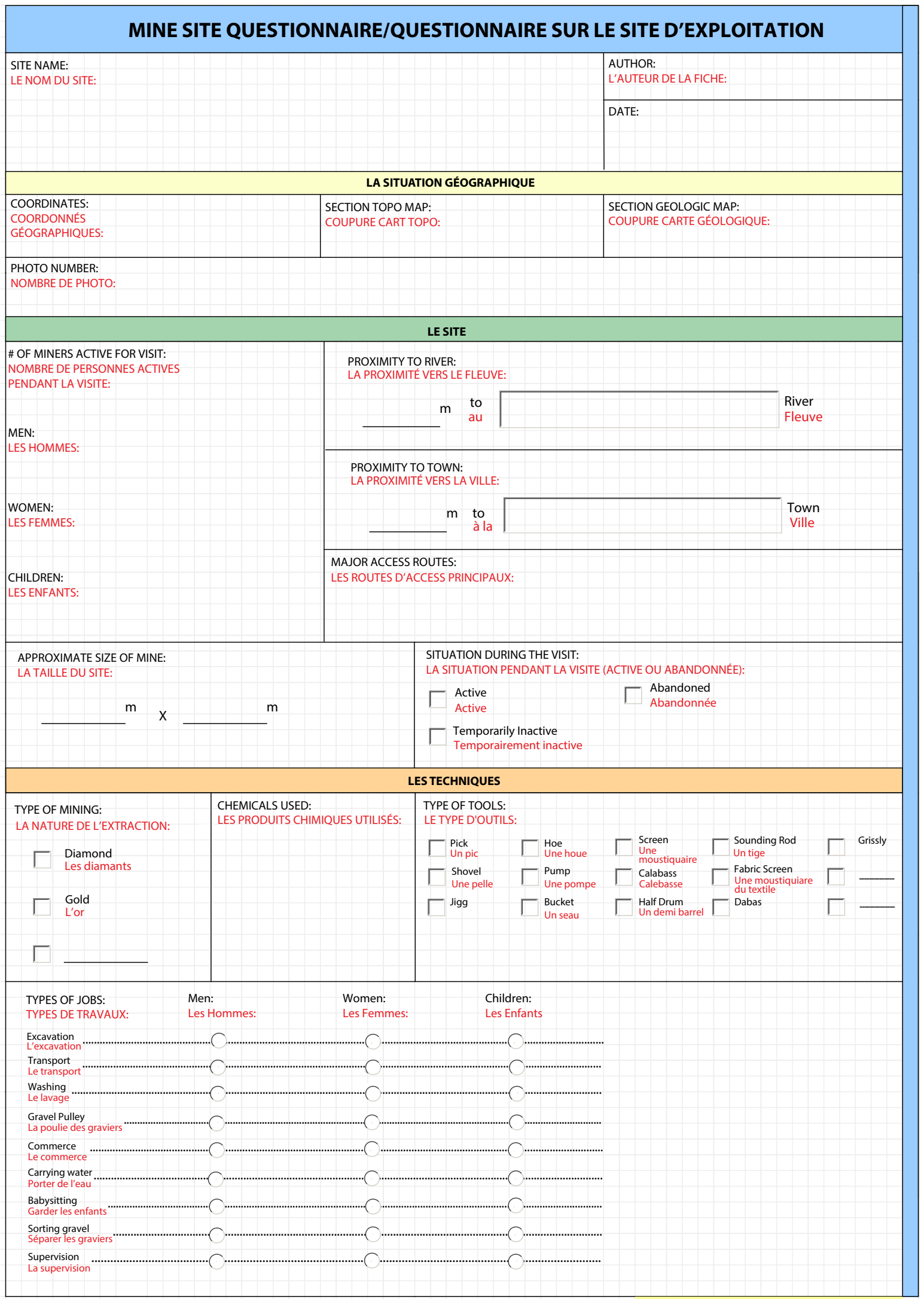




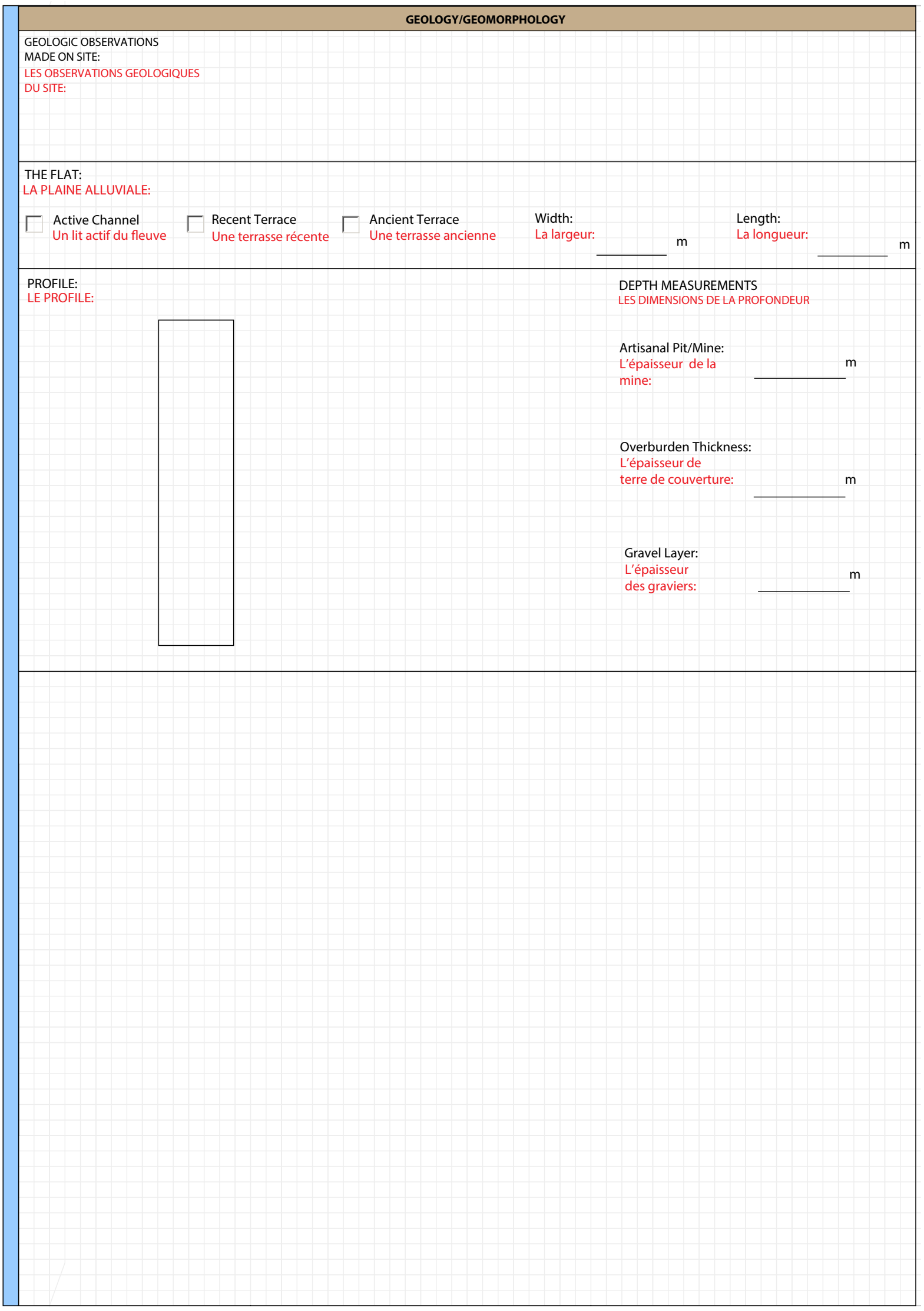




\section{Appendix 2. Mine Manager Data Sheet}

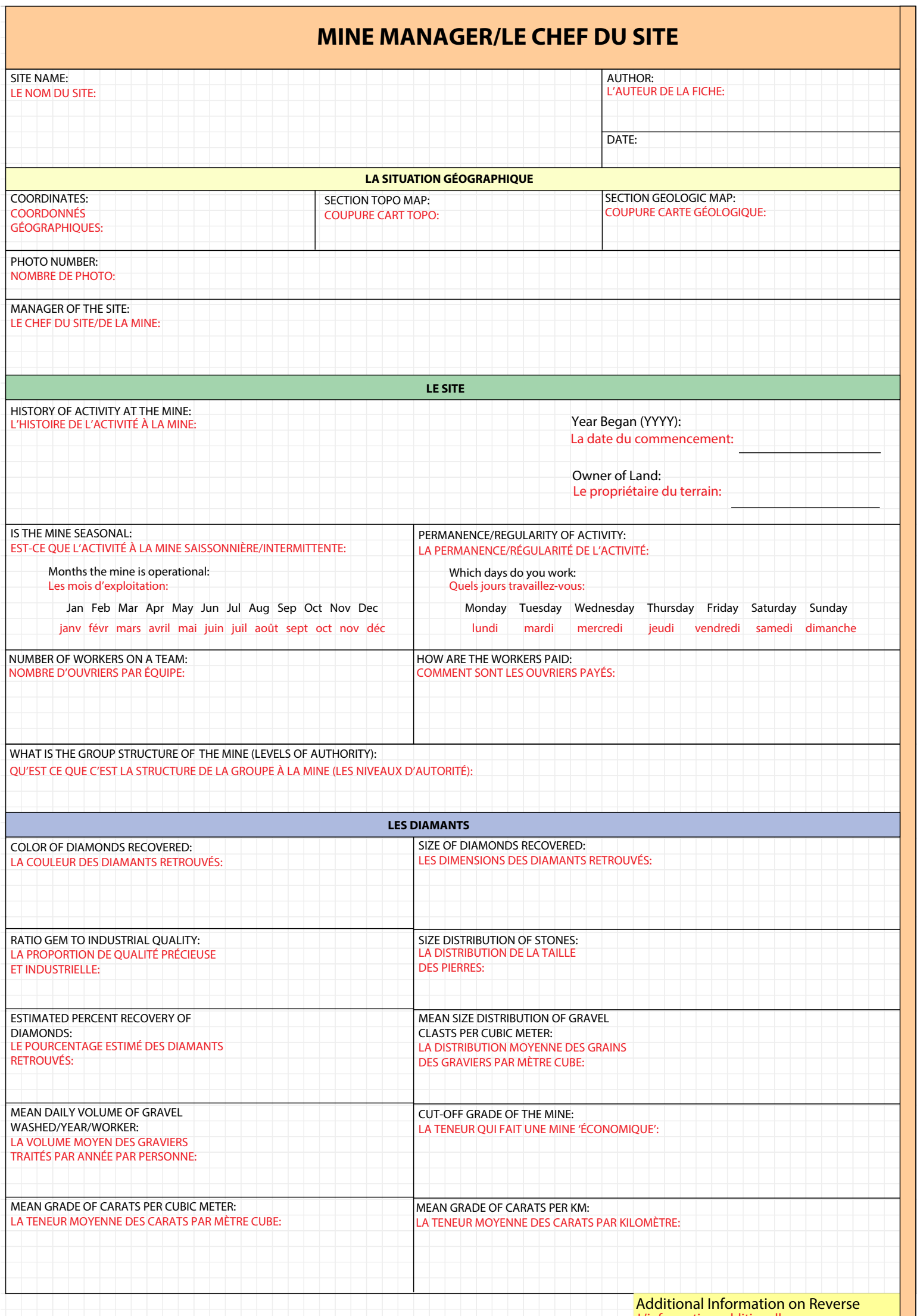


WHAT IS RECORDED WHEN THE DIAMONDS ARE SOLD (NAME,

CARAT WEIGHT, LOCATION, DATE):

QU'EST CE OU'IL EST NOTÉ APRÉS AVOIR VENDU LES DIAMANTS

(NOM, POIDS EN CARATS, LA LOCATION, LA DATE):

HOW MANY CARATS ARE MINED DAILY/WEEKLY/YEARLY

COMBIEN DE CARATS SONT RECOUVRIR CHAQUE SEMAINE/MOIS/ANNÉE:

LES PERMIS

PERMITS TO WORK THE LAND (WHO HAS

HOW MANY):

QUI POSSĖDE LES PERMIS D'EXPLOITER LE

TERRAIN/IL Y A COMBIEN DE PERMIS:

HOW DO YOU GET A PERMIT TO MINE?

HOW DO YOU GET A PERMIT TO MINE?
COMMENT EST-CE QU'ON OBTIENT UN PERMIS?:

QU'EST CE QUE LE PERMIS DEMANDE A VOUS?

HOLDERS OF EXPERT LICENSES (WHERE ARE
D'OU VIENNENT LES TENANTS DES PERMIS?:

MINE (REGISTERED OR NOT):

TYPES OF MINING EQUIPMENT

MINE (REGISTERED OR NOT):

TYPES OF MINING EQUPN

(ENREGISTRÉ OU NON):

QUEL TYPE D'OUTILS UTILISEZ-VOUS?

(MÉCANISÉ?):

DOES THE GOVERNMENT VISIT THE SITES (HOW OFTEN):

EST-CE QUE LES FONCTIONNAIRES VISITENT LES SITES

(ILS VISITENT TOUS LES COMBIEN?): 


\section{Appendix 3. Miner Life Data Sheet}

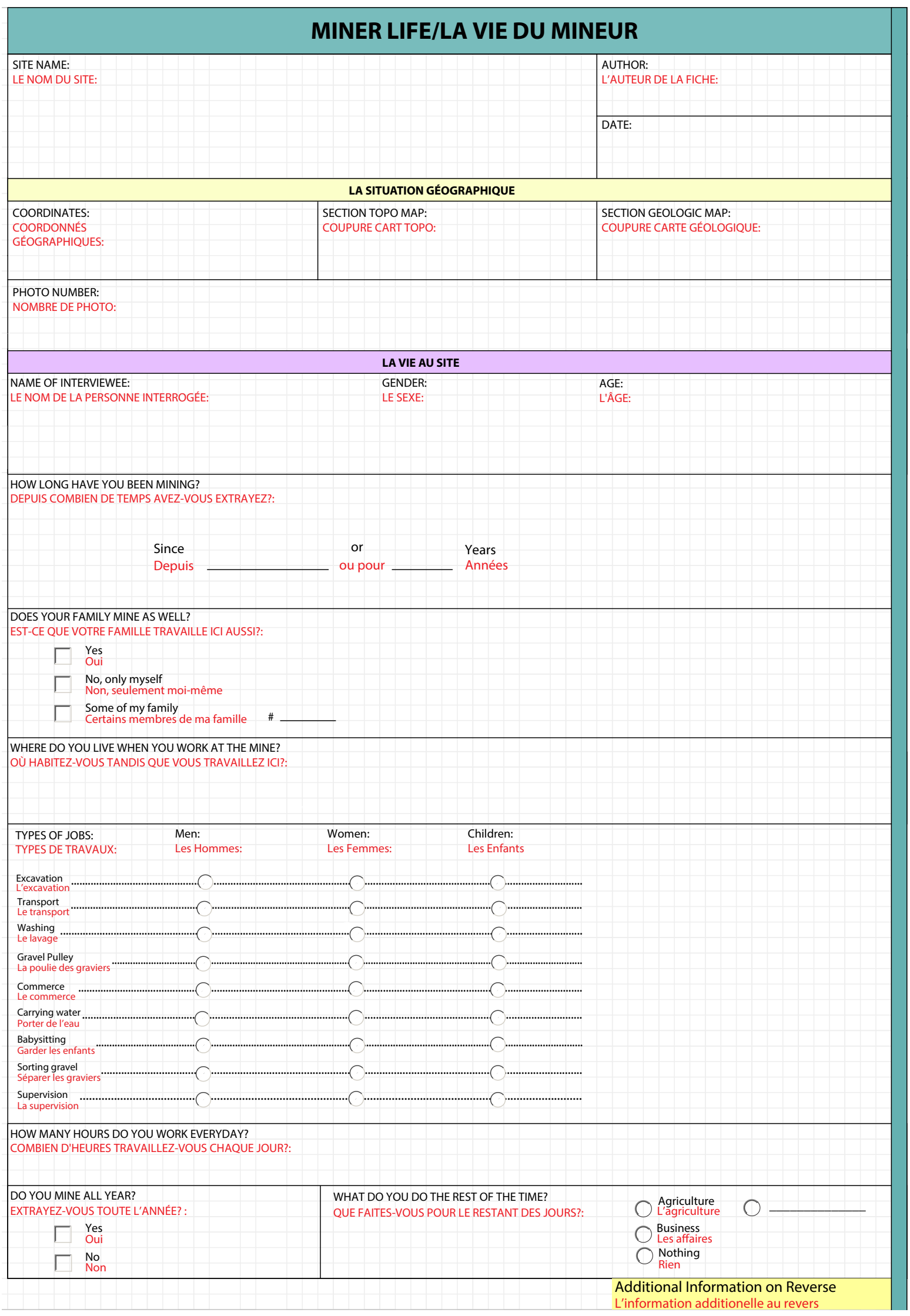


HOW DO YOU RECORD PRODUCTION?

NOTEZ-VOUS LA PRODUCTION?

WHAT TOOLS DO YOU USE? WHAT TOOLS DO YOU NEED?

OUEL TYPE D'OUTILS UTILISEZ-VOUS? AVEZ-VOUS BESOIN D'AUTRES OUTILS?

QUI POSSĖDE CES OUTILS? PAYEZ-VOUS POUR LES EMPLOYER?

VOUS TROUVEZ LES DIAMANTS TOUS LES COMBIEN?

WHAT IS THE BIGGEST DIAMOND THAT YOU'VE EVER FOUND?

QUELLE SONT LES DIMENSIONS DU PLUS GRAND DIAMANT QUE VOUS AVEZ TROUVÉ?

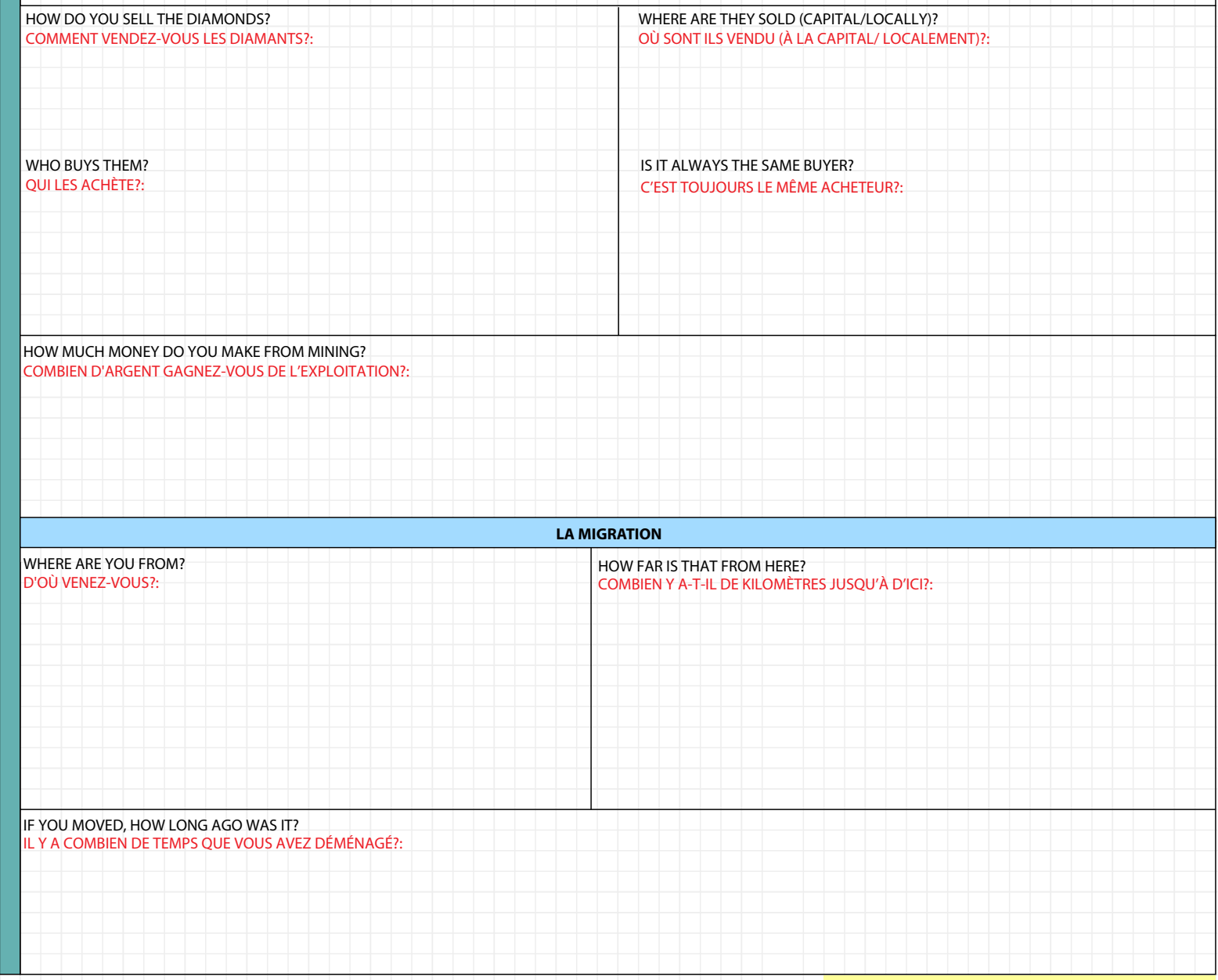

Additional Information on Reverse 


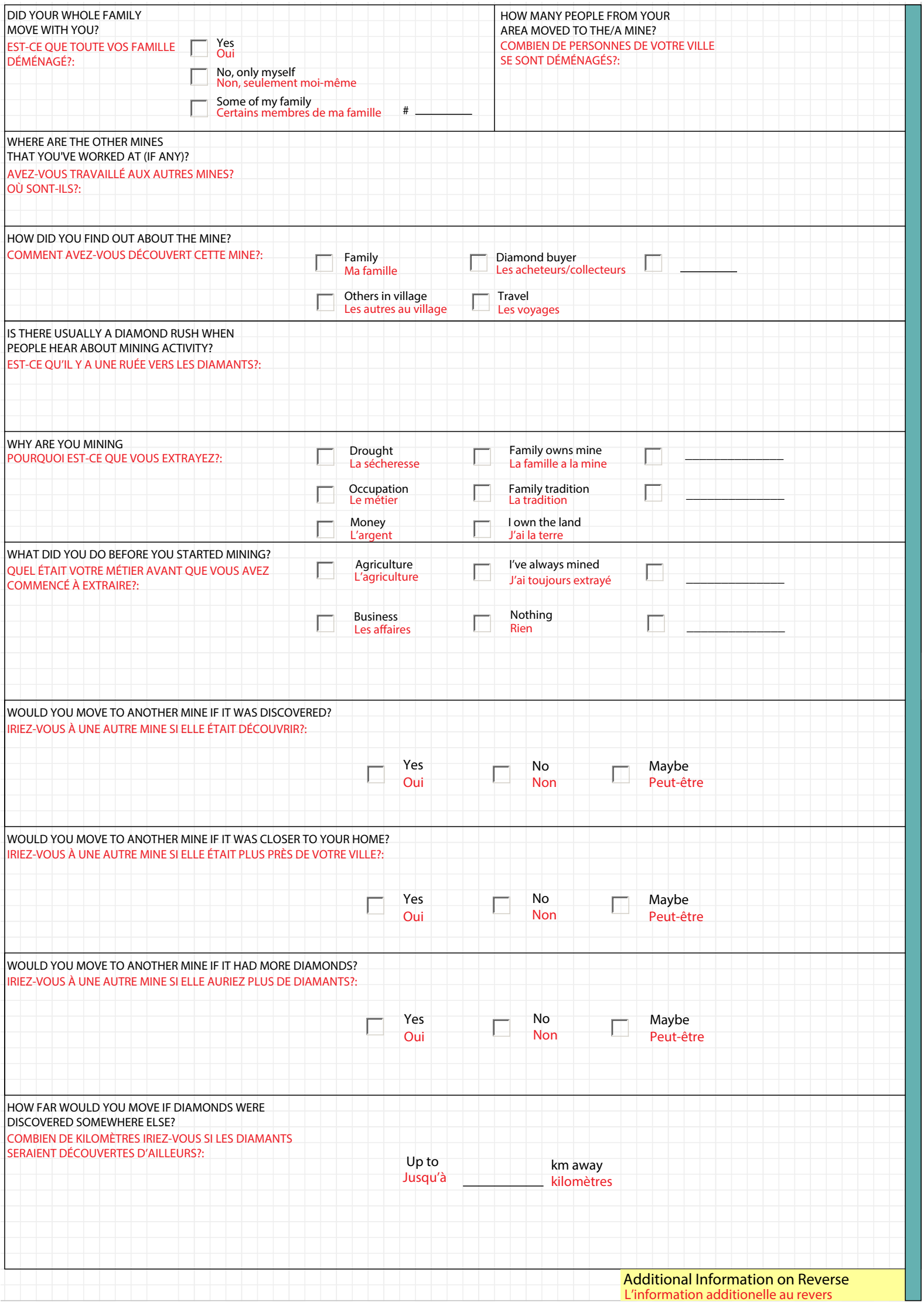





\section{$\frac{\mathbb{2}}{3}$}

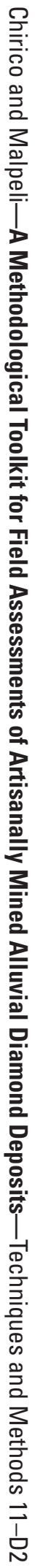

